\title{
Social Ills in Rich Countries: New Evidence on Levels, Causes, and Mediators
}

\author{
Jan Delhey ${ }^{1}$ (D) $\cdot$ Leonie C. Steckermeier ${ }^{1}$
}

Accepted: 9 December 2019 / Published online: 21 December 2019

(C) The Author(s) 2019

\begin{abstract}
The income inequality hypothesis claims that in rich societies inequality causes a range of health and social problems (henceforth: social ills), e.g. because economic inequality induces feelings of status anxiety and corrodes social cohesion. This paper provides an encompassing test of the income inequality hypothesis by exploring levels and breeding conditions of social ills in 40 affluent countries worldwide, as well as pathways for a subsample of wealthy European countries. Our aggregate-level research is based on a revised and updated Index of Social Ills inspired by Wilkinson and Pickett's book The Spirit Level, which we compile for both more countries (40) and more years (2000-2015) and combine with survey information about experienced quality-of-life as potential mediators. We get three major results: First, cross-sectionally income inequality is indeed strongly and consistently related to social ills, but so is economic prosperity. Second, while longitudinally changes in inequality do not result in changing levels of social ills, rising prosperity effectively reduces the amount of social ills, at least in Europe. Finally, whereas the cross-sectional analysis indicates that aspects of social cohesion most consistently mediate between economic conditions and social ills, the longitudinal mediation analyses could not ultimately clarify through which pathway rising prosperity reduces social ills. Overall we conclude that the income inequality hypothesis is, at best, too narrow to fully understand health and social problems in rich countries.
\end{abstract}

Keywords Prosperity $\cdot$ Income inequality hypothesis $\cdot$ Social ills $\cdot$ Health $\cdot$ Social cohesion $\cdot$ Spirit level theory $\cdot$ Status anxiety $\cdot$ Two-way fixed effects

\section{Introduction}

Growing income inequality in the majority of affluent countries has prompted social scientists to ask why income inequality is increasing (Rohrbach 2009; Dafermos and Papatheodorou 2013), and what the consequences are. The idea that gaping inequalities are bad for people and societies is at the heart of the income inequality hypothesis (henceforth inequality hypothesis): among rich societies, the theory suggests, the health of a population has

Jan Delhey

j.delhey@ovgu.de

1 Otto von Guericke University Magdeburg, Zschokkestr. 32, 39104 Magdeburg, Germany 
little or nothing to do with differences in prosperity, but everything to do with their income distribution (Wilkinson 1996; Kawachi 2000). While initially exclusively concerned with health outcomes (e.g. Rodgers 1979; Ben-Shlomo et al. 1996; Davey Smith 1996), the inequality hypothesis has since broadened to include other social problems.

The inequality hypothesis has recently been popularized by Wilkinson and Pickett's (2010) famous book, The Spirit Level, which embraces a broad range of health and social problems. ${ }^{1}$ The wider the income gap within nations, it is argued, the more a society is plagued by various social ills, ranging from low life expectancy to obesity to homicide. Consequently, the authors' key policy advice is the redistribution of economic resources, and they insist that further economic growth will not help (ibid., p. 25). This message reinforces a growing sentiment among both social scientists and the general public that greater wealth is no longer conducive to social progress and human wellbeing (Easterlin and Angelescu 2012; Skidelsky and Skidelsky 2013; Offer 2006).

One of The Spirit Level's strengths is certainly the range of social ills it addresses, whereas most other studies have dealt with single social ills, predominantly health outcomes. Its main weakness, however, is the simple methodology employed (cf. Saunders and Evans 2010; Hewlett 2011; Mills 2012), as well as the fact that the book hides many controversies that have evolved around the inequality hypothesis since its emergence some 40 years ago (e.g. Rodgers 1979). While a considerable number of cross-sectional studies, though by no means all, confirm core claims of the inequality hypothesis, there are comparably few longitudinal studies, which provide mixed evidence (as discussed later in more detail). Ultimately, Wilkinson and Pickett's book is silent about how much scholars are actually divided about the inequality thesis (cf., for example, Hill and Jorgenson 2018).

Four issues stand out. First, Wilkinson and Pickett do not seriously consider alternatives to inequality, such as economic prosperity, as determinants of social ills. Second, Wilkinson and Pickett settle for a cross-sectional analysis, without exploring whether, over time, increasing inequality causes more social ills. Third, while Wilkinson and Pickett ponder status anxiety as the key pathway that mediates between inequality and social ills at length, they present no original empirical evidence. Generally, there are few mediation analyses, particularly for the kind of objective macro-level social ills that are at the heart of the inequality hypothesis (an exception is Kragten and Rözer 2017). Fourth, the main index in The Spirit Level includes just 21 countries, mostly Western, and so it is questionable how far the geographical reach of the theory actually extends (cf. Saunders and Evans 2010).

The article at hand aims to bridge these gaps. Our starting point is the creation of a revised Index of Social Ills (ISI) modeled after Wilkinson and Pickett's index (2010), since treating social ills as a syndrome is arguably the most parsimonious way of testing the inequality hypothesis. We present evidence regarding this index for 40 rich countries (The Spirit Level: 21 countries) on an annual basis for the time period 2000-2015 (The Spirit Level: one point in time). In a first, cross-sectional step, the new index is utilized to examine, year by year, how strongly income distribution and economic prosperity are associated with social ills. In a second, longitudinal step we consider whether changes in income inequality (and economic prosperity, respectively) worsen (attenuate) social ills. The third and final step is to put status anxiety, the mechanism highlighted by Wilkinson and Pickett, to an empirical test, along with other potential mechanisms that might mediate between economic conditions and social ills. Overall, we provide an encompassing examination of

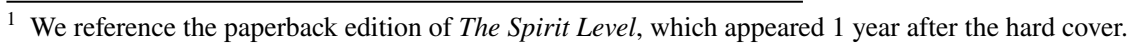


the inequality hypothesis based on an index of social ills, which to our best knowledge is a novelty. Although we do find that income inequality and social ills are robustly associated in cross-sections of rich countries, the longitudinal results challenge core claims of the inequality hypothesis.

The article proceeds as follows: the next two sections briefly introduce The Spirit Level within the context of the inequality hypothesis and discuss related research in order to demonstrate the core theoretical claims, to explain the main research gaps and to develop hypotheses that will guide our research. For this purpose, the inequality hypothesis is split into its two constituent parts: the link between societal-level inequality and social ills, and the issue of mediation. Section 4 describes the country selection, data collection, key variables, and analytical strategy. Section 5 presents our findings for both parts of the theory, which are finally discussed against the background of the inequality hypothesis generally, and The Spirit Level specifically.

\section{Why Countries are Plagued by Social Ills: Theory and Previous Findings}

\subsection{The Inequality Hypothesis and the Spirit Level}

The inequality hypothesis is a middle-range theory about the role that (income) inequality plays in population health and other outcomes that indicate a 'healthy' state of society, focusing on developed countries. Originating from Health Science, it evolved over the years into a general social science theory that has been applied to a broad range of objective social problems, and even to subjective well-being (cf. Wilkinson and Pickett 2017). Even if narrowed down to health, however, research scholars are still divided about the inequality hypothesis after more than three decades, as several comprehensive reviews demonstrate (Judge et al. 1998; Lynch et al. 2004a, b). Although at any given point in time more equal countries do often have healthier populations and are less problem-ridden, there is little evidence that a change towards less inequality within countries translates into fewer social ills.

Against this complex background, Wilkinson and Pickett launched The Spirit Level as a popularized version of the inequality hypothesis. In the book, they explain which social outcomes are corroded by inequality: those which carry a negative social gradient, that is, which are more common among people at the bottom of society than at the top (Wilkinson and Pickett 2010, p. 27). The Index of Health and Social Problems that Wilkinson and Pickett suggest includes a range of ten problems with a negative social gradient. Rich countries perform very differently on this index, and the amount of income inequality is given as the prime reason. Occupying the lower ranks literally makes people sick because of the status anxiety involved, and thus a more egalitarian distribution of income and wealth would lead to a better society with fewer social ills. In contrast, greater affluence would be ineffective: "The problems in rich countries are not caused by the society not being rich enough (or even by being too rich) but by the scale of material differences between people within each society being too big" (Wilkinson and Pickett 2010, p. 25).

A strength of the Spirit Level is its attempt to generalize the inequality hypothesis to a broader yet clearly defined range of social ills, and the proposed index specifically renders a parsimonious test of the theory possible. These are the assets on which we are going to build, and to the best of our knowledge, there is no study which has employed a revised and 
updated Index of Health and Social Problems. In this context, the Misery Index (Saunders and Evans 2010) is not pertinent, as its components are either not characterized by a social gradient, or have a reversed social gradient. At the same time, the analyses presented in The Spirit Level are simplistic (O'Connell 2010; Saunders and Evans 2010), and this low methodological profile is in conflict with the bold causal claims made (Rambotti 2015). As Subramanian and Kawachi (2004, p. 89) have argued, scientific progress on the inequality hypothesis "[...] depends on a combination of better data, more sophisticated analytical methods, and more rigorous application of theory and mechanisms connecting income inequality to public health". The plan in this study, therefore, is to revise and update Wilkinson and Pickett's index for both a larger number of wealthy countries and more points in time; to examine its association with income inequality (and economic prosperity) in a more rigorous way that includes both cross-sectional and longitudinal analyses; and, finally, to shed light on potential mechanisms that convert economic conditions into social ills.

\subsection{Improving on the Index of Social Ills and the Issue of Country Coverage}

The Index of Health and Social Problems includes distrust, mental illness (including drug and alcohol addiction), life expectancy and infant mortality, obesity, children's educational performance, teenage births, homicides, imprisonment rates, and social mobility. Although we find the idea of an index compelling, we see three (minor) problems with Wilkinson and Pickett's choice. For one, all components involve objective indicators except social trust, which could be streamlined. Moreover, social trust is often regarded as a mechanism rather than an outcome (e.g. Elgar and Aitken 2011, Wilkinson 1996). Second, one component—social mobility-blurs the distinction between the key independent variable, economic inequality, and the social outcome, as both are part of the stratification regime (Grusky 2001). To avoid these conceptual ambiguities, we suggest omitting social trust and social mobility from the index. Third, the transparency about missing data generally could be improved: for example, The Spirit Level reports social mobility data for just eight countries, and so it is unclear how they can form part of an index which is reported for all 21 countries.

There have been accusations of cherry-picking regarding the countries covered (Saunders and Evans 2010; Snowdon 2010), as the means by which Wilkinson and Pickett reduced their initial sample of the 50 richest countries worldwide to the final set of 21 in their overall index is not very transparent. One justification given for dropping countries was the non-availability of income distribution data (Wilkinson and Pickett 2010, p. 275), but there is data on more countries available, both now and then. The other justification was the exclusion of tax havens; to this end, Wilkinson and Pickett indifferently discard all countries with a population of less than three million, which for obvious reasons is a questionable choice. Ultimately, increasing the number of countries is not only an issue of gaining statistical power, but also of better representing the cultural variety of rich nations (Saunders and Evans 2010; Snowdon 2010). With the exception of Japan, the countries covered in the original Index of Health and Social Problems are exclusively Western.

\subsection{Developing Hypotheses About Determinants of Social Ills}

With a refined index and a broader set of rich countries, we test the core claims of the inequality hypothesis as spelled out by Wilkinson and Pickett (2010), most notably for 
economic inequality. From a cross-sectional perspective, the theory, along with extensive research, leads us to expect:

$\mathrm{H} 1$ (cross-sectional) Across rich societies, income inequality is positively associated with a bundle of social ills.

The detrimental effects of economic inequality have been found for life expectancy and infant mortality (Babones 2008), obesity (Su et al. 2011), mental health (Layte 2012), selfreported depressive symptoms (van Deurzen et al. 2015), and homicides (Chamlin and Cochran 2006). ${ }^{2}$ Similarly, there is evidence that greater income inequality is associated with weaker solidarity (Paskov and Dewilde 2012), less civic participation (Lancee and van de Werfhorst 2012), more school bullying (Elgar et al. 2009), and lower subjective health (Whelan and Layte 2014). There is also contrary evidence, such as for life expectancy (Pop et al. 2013) and social trust (Steijn and Lancee 2011), but it seems that many cross-sectional studies confirm the corrosive effect of (income) inequality.

A serious examination of the assumed corrosive impact of inequality requires controlling for other country characteristics that might affect the number of social ills in a given society. As a minimum, economic prosperity should be considered, as richer countries also tend to have a more equal income distribution (Ferreira and Ravallion 2009). Empirically, controlling for prosperity when analyzing the potential corrosive effect of economic inequality can make a difference (see Steijn and Lancee 2011; Zagorski et al. 2014; Kelley and Evans 2017). Taking economic prosperity into account is also important on theoretical grounds, as proponents of the inequality thesis typically present national income as an outdated social force in the quest for progress-useful in the past, but no longer:

H2 (cross-sectional) Across rich societies, economic prosperity is not associated with a bundle of social ills.

This uselessness, however, is posited rather than demonstrated. Wilkinson and Pickett's thinking, critics say, "rests on the fundamental misconception that anything that is not essential has no benefit, except as a status symbol" (Snowdon 2010, p. 106), denying that people in wealthy countries may derive absolute utility from financial resources. To the extent that they do, prosperity might still be a progressive force. For example, a higher national income means more money to tackle social problems. Empirically, there is evidence in highly developed countries that prosperity matters independently of income distribution-for example, for population health (Kennelly et al. 2003; Pop et al. 2013), bonds of social cohesion (Dragolov et al. 2016), and individual quality of life (Delhey and Steckermeier 2016; Zagorski et al. 2014). It might well be that economic prosperity has not done its job in making lives and societies better.

Another cross-sectional hypothesis can be derived from the claim that the inequality thesis holds for rich countries generally, not only the Western world:

\footnotetext{
${ }^{2}$ In our review, we largely focus on cross-national comparisons of objective social ills across wealthy countries to fit the declared scope of the theory and the design of our own empirical analysis, presented later.
} 
H3 (cross-sectional) The positive association between income inequality and social ills is equally strong in culturally more homogeneous and more heterogeneous samples of rich countries.

This universalistic assumption has been questioned. Saunders and Evans (2010) and Snowdon (2010) argue that social ills might also reflect societies' deep-rooted cultures, so that structural conditions such as income inequality (and economic prosperity, too) could be a weaker determinant of social ills in culturally more diverse country samples. We examine this issue by systematically comparing results from two inter-related sets of rich countries: a global set of 40 countries, and a European subset of 29 countries, as described in Sect. 4.

The litmus test for the inequality hypothesis certainly involves a longitudinal perspective, as this is the best way to establish causality:

H4 (longitudinal) Across time, in rich countries a changing income inequality-but not economic prosperity-induces changing levels of social ills.

As already touched upon, there are many fewer pertinent longitudinal than cross-sectional studies. The majority do not unearth a detrimental effect of inequality over time for health outcomes (e.g. Beckfield 2004; Shkolnikov et al. 2011). Often, income inequality is relevant for poorer health outcomes across countries, but not across time in a number of studies (e.g. Leigh and Jencks 2007; Avendano 2012; Hu et al. 2015). Still, some longitudinal studies do support the inequality hypothesis, for health (Torre and Myrskylä 2014; Neumayer and Plümper 2016) and other outcomes (imprisonment: Sutton 2004; obesity: Vogli et al. 2014; homicide: Lafree and Tseloni 2006). The latter study by Lafree and Tseloni, however, combines economic prosperity and income equality, and so it is difficult to tell which determinant is ultimately responsible for the changing homicide rates.

\section{From Inequality to Social Ills: The Search for Mechanisms}

\subsection{Status Anxiety and Social Cohesion as the Favored Mediators}

At the heart of the income inequality thesis lies the question of how inequality translates into social ills, which is another ongoing controversy (cf. Phillips 2006, ch. 7). In The Spirit Level, a social psychological pathway has moved into the center of attention, namely status anxiety — a broad syndrome of status-related concerns (Wilkinson and Pickett 2010, p. 40). The argument is that people worry more about their social status and how they are evaluated by fellow citizens in more unequal environments, which in turn generates the various social ills, as people react to evaluative stress with behavior that harms themselves and others (cf. also Delhey et al. 2017):

H5 (cross-sectional and longitudinal) Across rich societies and across time, status anxiety mediates between inequality and the amount of social ills.

Most studies have interpreted status anxiety as feelings of inferiority - the "feeling of not counting much in the eyes of others" (ibid., p. 218)—, an approach our study will adopt. In line with The Spirit Level, a more unequal income distribution has been 
found to come along with heigthened feelings of inferiority in a cross-European comparison (Delhey and Dragolov 2014; Whelan and Layte 2014; Delhey et al. 2017), in turn undermining individual life satisfaction and mental health. Another study which operationalized status anxiety as the degree to which people are driven into social comparisons confirms the link between inequality and status anxiety, but not between anxiety and the negative outcome of individual depressive symptoms (van Deurzen et al. 2015). Finally, individual status seeking, yet another approach to examine status anxiety, was not found to be higher in more unequal countries (Paskov et al. 2017). No study has so far used measures of status anxiety in a country-level mediation analysis, either cross-sectionally or longitudinally.

The prime alternative pathway in the inequality hypothesis debate has for a long time been social cohesion/social capital (Wilkinson 1999; Kawachi and Berkman 2000; Kennelly et al. 2003). By increasing social distance and crushing shared interests, "inequality is strongly and systematically related to the character of social relations and the nature of the social environment in a society" (Wilkinson 1999, p. 526).

H6 (cross-sectional and longitudinal) Across rich societies and across time, experienced social cohesion mediates between inequality and the amount of social ills.

In the empirical section below, we consider population levels of social trust, satisfaction with social life, and the feeling of being excluded as expressions of social cohesion. Some aggregate-level studies of richer nations confirm the corrosive effect of inequality on social cohesion-or at least a negative association-(Böhnke 2004; Dragolov et al. 2016; Kragten and Rözer 2017), while others, applying multi-level designs, do not find such an effect on individual social capital (Steijn and Lancee 2011; van Deurzen et al. 2015). The evidence from aggregate-level mediation analysis is also mixed: whereas one study finds citizen trust levels to mediate between inequality and population health both cross-sectionally and in a pseudo-panel analysis (Kragten and Rözer 2017), another aggregate panel study does not suggest an effect of trust on population health (Kennelly et al. 2003).

\subsection{Further Considerations on Mediators}

An alternative to status anxiety and social cohesion, which ultimately both concern the quality of social life, is economic strain. Originating from criminology and the sociology of social problems, strain theory states that pressure, including economic strain, works as a stressor and therefore increases the likelihood of crime and deviance. Merton's (1938) classic anomie theory, and also general strain theory as developed by Agnew and White (1992), emphasize the struggle for financial success, arguing that strain arises when people are faced with a gap between their internalized success goals and their current status, with crime and deviant behavior as one of several behavioral responses. Consequently, crime rates (and other social ills) could be systematically higher in societies in which many people experience economic strain, as indicated by dissatisfaction with financial conditions, for example, or difficulties in making ends meet.

H7 (cross-sectional and longitudinal) Across rich societies and across time, experienced economic strain mediates between inequality and the number of social ills. 
According to Whelan and Maitre (2013), national income levels and inequality had no direct effect on economic stress. Another study confirmed this lack of effect of inequality on financial (dis)satisfaction, further finding that people in wealthier countries are financially more satisfied (Zagorski et al. 2014).

So far, we have discussed potential mediators exclusively with reference to social inequality, however, provided there is a link between economic prosperity and social ills, there are good reasons to assume that the above-mentioned mediators work for prosperity as well. Under the assumption that people still derive absolute utility from income, then status anxiety (Delhey and Dragolov 2014) and economic strain (Zagorski et al. 2014) could be less widespread in richer societies, and in turn lead to fewer social ills. Prosperity might also strengthen social cohesion, as abundant economic resources dampen distributive conflicts and shift preferences from material to post-material concerns (Inglehart 1997). Supporting this argument, cross-national comparisons have established that richer countries tend to have stronger bonds of social cohesion generally (Dragolov et al. 2016) and of social trust specifically (Delhey and Newton 2005).

\section{Data and Methods}

\subsection{Case Selection}

We started with a list of 72 countries that were ranked as 'high income' in 2015 according to the World Bank's classification (Fantom and Serajuddin 2016) and were ranked as at least 'upper middle income' ${ }^{3}$ in at least $90 \%$ of the years between 2000 and 2015, our period of examination. We then excluded ten countries with jurisdictions that, according to the OECD, have not implemented the internationally agreed tax standard, so that we were able to eliminate tax havens. ${ }^{4}$ Twelve small states with a current (2015) population of less than 300,000 were excluded, as social processes might work differently in smallscale and regionally compact societies. The sample was further reduced by three countries because information on social ills was missing, and a further seven countries, due to missing key explanatory variables. The selection process is documented in detail in Table 6 in the appendix. Finally, our study involves 40 rich countries, almost twice as many as in The Spirit Level, and is less Western-centric, as it contains seven non-Western countries. In order to learn more about how the larger geographical reach affects results, we perform, whenever possible, analyses on the full global sample (all 40 countries), and a European sub-sample (29 countries). For reasons explained below, the mediation analysis can only be performed for European countries.

\footnotetext{
3 The income thresholds are drawn from the World Bank's World Development Indicators, which use GNI per capita in US\$ (Atlas methodology) to characterize countries as low income (L), lower middle income (LM), upper middle income (UM), and high income $(\mathrm{H})$.

4 OECD Progress Report: A Progress Report on the Jurisdictions surveyed by the OECD Global Forum in Implementing the Internationally Agreed Tax Standard, 2 April 2009.
} 


\subsection{Data}

\subsubsection{The Index of Social Ills}

Of the original ten indicators that Wilkinson and Pickett (2010) included in their index, six are included in our Index of Social Ills (ISI): life expectancy, infant mortality, obesity, teenage birth rate, homicides, and imprisonment. We did not include trust, due to its rather subjective nature of measurement and its conceptual ambiguity (see above); we further excluded mental illness, educational scores, and social mobility for reasons of data availability, and decided against alcohol consumption as an indicator of drug use - which Wilkinson and Pickett incorporate in mental illness without further explanation-as alcohol consumption reflects a positive, rather than negative, social gradient.

The data for life expectancy, infant mortality, teenage birth rate, and homicides was obtained from the World Bank. The obesity data was drawn from the World Health Organization, and the imprisonment data from the World Prison Brief database. As some of the data is not available for every year (prison rate is only available approximately every 2 years; on intentional homicides, eleven countries have more than 1 year missing), we replaced missing values using linear interpolation.

\subsubsection{Construction of the Index of Social Ills}

Like Wilkinson and Pickett's index, our own Index of Social Ills (ISI) does not measure an underlying latent dimension of social failure but is instead a formative construct consisting of a bundle of health problems and social problems with a proven negative social gradient. As none of the six components (life-expectancy is reversed) are negatively related in any of the years from 2000 to 2015 there is no indication that they cancel each other out. Separate analyses for the ills which have worsened between 2000 and 2015 (obesity and imprisonment) and the ills which have improved (life expectancy, infant mortality, intentional homicides and adolescent birth rate) do not yield different results from the analysis of the full index. The ISI is thus composed as an unweighted additive formative index of the following standardized variables:

$$
\begin{aligned}
I S I= & \frac{\text { life expectancy }}{6}+\frac{\text { infant mortality }}{6}+\frac{\text { teenage pregnancy }}{6}+\frac{\text { intentional homicides }}{6} \\
& +\frac{\text { (obesity rate female }+ \text { obesity rate male }) / 2}{6}+\frac{\text { prison rate }}{6}
\end{aligned}
$$

In 2015, the most recent year covered, the ISI ranges from -1.97 in Japan to 2.03 in Trinidad and Tobago. Averaged over the period 2000-2015, the countries least affected by social ills were Japan $(-1.71)$, South Korea $(-1.15)$, and Singapore $(-0.94)$, and those most affected are Trinidad and Tobago (2.09), Uruguay (1.35) and the United States $(1.31) .^{5}$

\footnotetext{
${ }^{5}$ ISI values by year are shown in Table 7 in the appendix.
} 


\subsubsection{Economic Conditions}

We operationalize income inequality using the Gini coefficient of income distribution ranging from 0 to 100, with higher values indicating higher inequality. During 2000-2015, income inequality was lowest in Denmark (23.38) and highest in Chile (49.50). Economic prosperity is measured as log GDP per capita, PPP (in current Int. \$). In our full sample, $\log$ GDP ranges from $9.45(\sigma: 0.26)$ in Uruguay to $11.16(\sigma: 0.24)$ in Luxembourg. The Gini data was drawn from Frederick Solt's (2016a, b) Standardized World Income Inequality Database (SWIID), the GDP data was obtained through the World Bank. ${ }^{6}$ Income inequality and economic prosperity are negatively correlated, yet over time with decreasing strength and statistical significance in the full sample, and with increasing strength and significance in the European sub-sample.

\subsubsection{Quality-of-Life Mechanisms}

Indicators for the mechanisms are all drawn from the European Quality of Life Survey (EQLS) waves 2003, 2007, and 2011. Twenty five of our European countries are included in all three waves, with numbers of individual observations varying from around 600 to more than $2000 .^{7}$ The number of missing values is extremely low for the variables employed to operationalize our mediators of interest $(<4 \%)$. We therefore did not apply imputation measures, but a list-wise deletion of missing cases.

We operationalize status anxiety using two separate questions that are asked only in the second and third waves of the EQLS: "Some people look down on me because of my job situation or income" and "I feel that the value of what I do is not recognized by others", each measured on a five-point scale from 1 (strongly disagree) to 5 (strongly agree). While the first item refers directly to a feeling of inferiority resulting from one's economic situation, the second item includes a more general need to be appreciated by others. In previous research these questions have been used to measure status anxiety, either individually (Layte 2012; Whelan and Layte 2014) or combined in an additive index (Delhey et al. 2017; Steckermeier and Delhey 2019).

We used three items in order to examine social cohesion: generalized social trust, satisfaction with social life, and the feeling of being left out of society. Generalized trust is measured on a ten-point scale from 1 (you can't be too careful) to 10 (most people can be trusted). People's satisfaction with their social life is measured on a ten-point scale from 1 (very dissatisfied) to 10 (very satisfied). 'I feel left out of society' offers a five-point scale from 1 (strongly disagree) to 5 (strongly agree). In the EQLS 2003, this item was measured on a four-point scale without the middle category 'neither agree nor disagree'. The 2003 variable has thus been recoded to match the 2007/2011 coding and now includes an empty middle category.

To capture economic strain, we drew on people's satisfaction with their living standard and their evaluation of how easily their household makes ends meet. Satisfaction with one's living standard is measured on a ten-point scale from 1 (very dissatisfied) to 10 (very

\footnotetext{
${ }^{6}$ Means and standard deviations of income inequality and economic prosperity are provided in Table 8 in the appendix.

${ }^{7}$ For the full list of countries, observations, and response rates by wave see Table 9 in the appendix.
} 
Fig. 1 Mediation model

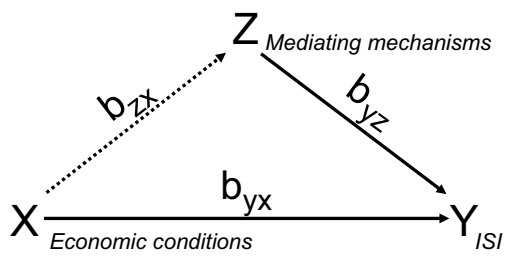

satisfied). Making ends meet ranges from 1 (with great difficulty) to 6 (very easily) on a six-point scale.

All items are divided by the number of categories to range from 0 to 1 , higher values indicating a more negative feeling/assessment for negatively-phrased items (e.g., not feeling valued) and more positive feelings/assessment for positively phrased items (e.g., people can be trusted). Each country is assigned the mean values of its respondents for each of the survey waves separately. ${ }^{8}$

\subsection{Methods}

The ideal model with which to address our research questions would be a macro-micromacro mediation, estimating the effects of the country-level economic conditions on individual-level mediators and then the effects of the mediators on the country-level ISI. The second step would involve micro-macro multilevel modeling, for which analysis techniques are scarce (Croon and van Veldhoven 2007). We thus follow the classic approach of aggregating all variables that are not already measured at the country level (in other words, the potential mediators) by assigning the mean score of the respective country respondents to countries. This approach leaves us with a relatively small number of cases (40 countries), but a reasonable number of observations over time (640 observations in 16 years). As the economic conditions changed only moderately over the observation period of 16 years, we apply both pooled OLS to estimate cross-sectional effects, and two-way fixed effects regressions (TWFE) to model effects over time.

The subsequent analysis is tripartite. First, to examine the relationship between the ISI and income inequality and economic prosperity, we study Pearson's correlations by year for each of the two economic conditions separately. Second, we estimate pooled OLS and TWFE regressions of ISI on the economic conditions considered simultaneously. Third, we finally examine what mediates the relationship between economic conditions and the ISI, cross-sectionally and over time.

This final step three of the analysis presupposes two further estimations (see Fig. 1): beyond the direct effect of the economic conditions on the ISI which are estimated in Step 2 , we need to estimate the effect of the economic conditions on the mediators $\left(b_{\mathrm{zx}}\right)$ and the effect of the mediators on the ISI while controlling for the direct effect of the economic conditions $\left(\mathrm{b}_{\mathrm{yz}}\right)$. We apply structural equation modelling (SEM) for the cross-sectional models which allows us to estimate all pathways simultaneously. We estimate two separate models for the panel analysis, one for $\mathrm{b}_{\mathrm{zx}}$ alone and one for $\mathrm{b}_{\mathrm{yx}}$ and $\mathrm{b}_{\mathrm{yz}}$ simultaneously.

\footnotetext{
${ }^{8}$ Mean values and standard deviations of the mediators are reported in Table 10 in the appendix.
} 


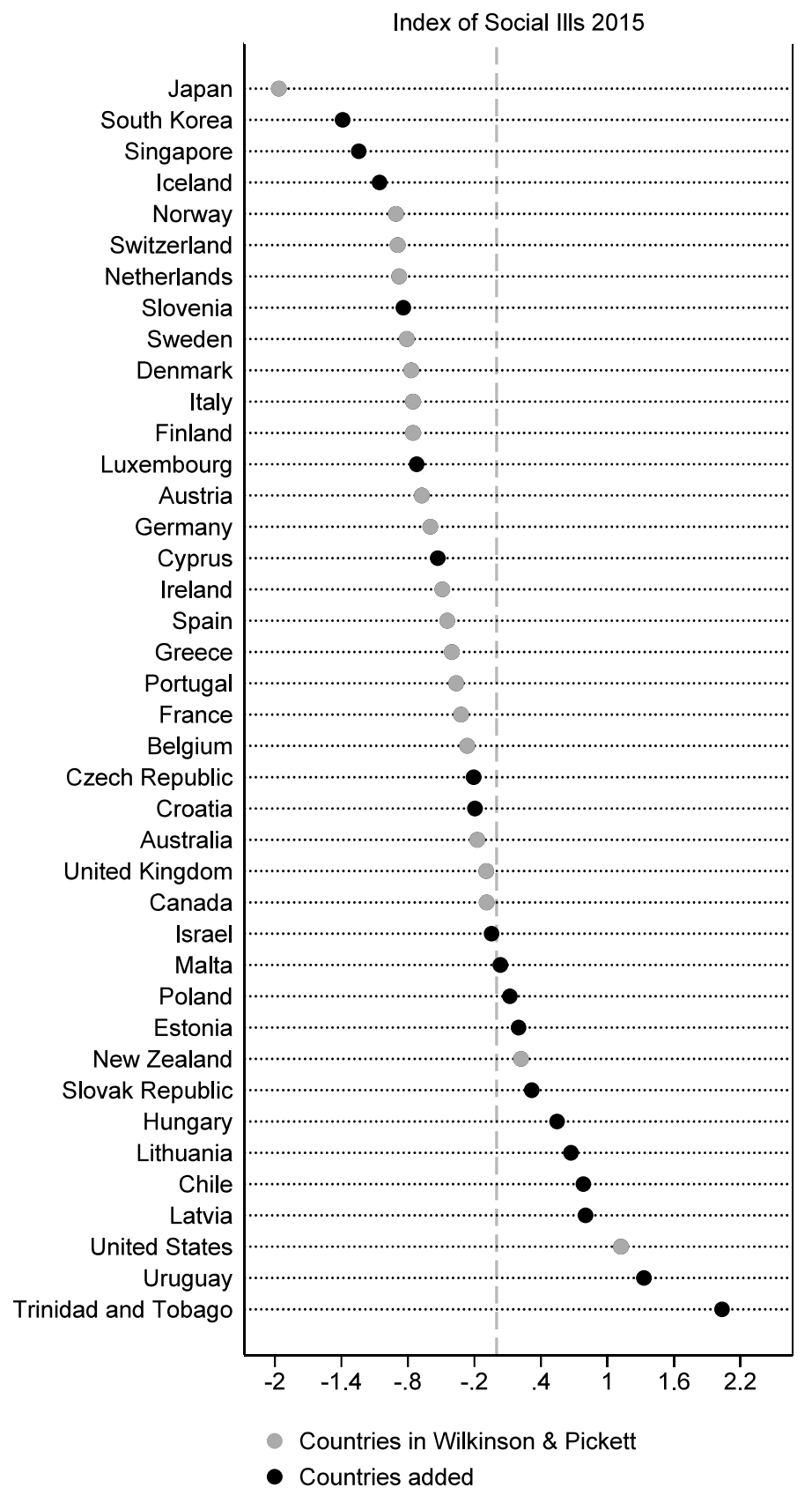

Fig. 2 Distribution of social ills in 40 affluent countries 2015

Steps one and two of the analysis are undertaken for the full (global) country sample as well as for the 29 European countries, while the mediation analysis-Step three-just involves a smaller European sub-sample $(n=25)$, as our items examining the mechanisms 
are taken from the EQLS. We report four levels of significance throughout Sect. 5: ${ }^{\dagger} p<0.10, * p<0.05, * * p<0.01$, and $* * * p<0.001$. The variables are time delayed for all steps of the analysis: economic conditions are lagged by 1 year in relation to potential mediators (the experienced quality of life of a population), and by 2 years related to the ISI. The mediators are thus lagged by 1 year pertaining to ISI. As the ISI covers the period from 2000 to 2015, economic conditions range from 1998 to 2013. The mediators are available for 2003, 2007, and 2011 only, and consequently relate to economic conditions for 2002 , 2006, and 2010, and to the ISI for 2004, 2008, and 2012.

\section{Results}

\subsection{Descriptive Analysis}

Figure 2 shows the prevalence of social ills in 2015 among 40 rich countries, as measured using our social ills index. Five groups of countries can be differentiated, moving from problem-ridden to problem-free. Trinidad and Tobago, Uruguay, the United States, Latvia, Chile, Lithuania, and Hungary comprise a group of countries plagued by a very high number of social ills. These seven countries are the only countries with ISI scores of 0.5 and higher over the full period from 2000 to 2015. Trinidad and Tobago stand out as particularly problem-ridden, with a standardized score of more than two. Another geographically mixed cluster of three countries, comprising the Slovak Republic, New Zealand, and Estonia, scores above average on the index, with scores between 0.2 and 0.5 . The middle of the distribution (ISI scores smaller than \pm 0.2 ) includes further Anglophone countries, as well as Poland, Israel, and Croatia. The remaining 23 countries (all scoring values smaller than -0.2) are exclusively European and Asian. Sixteen of these countries score values lower than -0.5, of which six-Sweden, Switzerland, Iceland, Singapore, South Korea, and Japan-experienced very low levels of social ills across the full observation period 2000-2015. This ranking is largely in line with Wilkinson and Pickett's (2010) original ranking $\left(r_{s}=0.81, N=21\right)$. Of the 19 countries

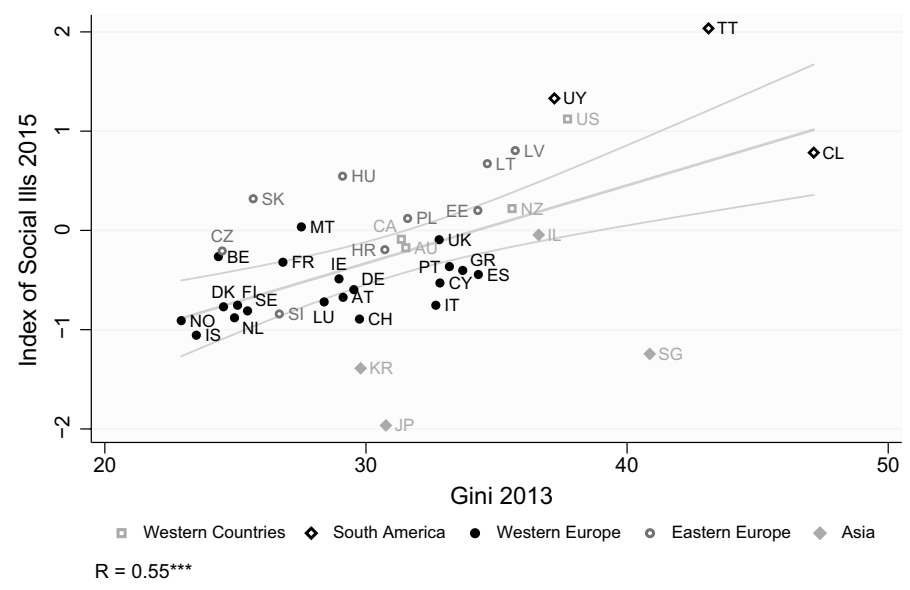

Fig. 3 Relationship between the ISI and income inequality. Note: Pearson's Correlations $(\mathrm{N}=40)$. All economic conditions are lagged by 2 years, i.e. Income Inequality 2013 corresponds to Index of Social Ills 2015 


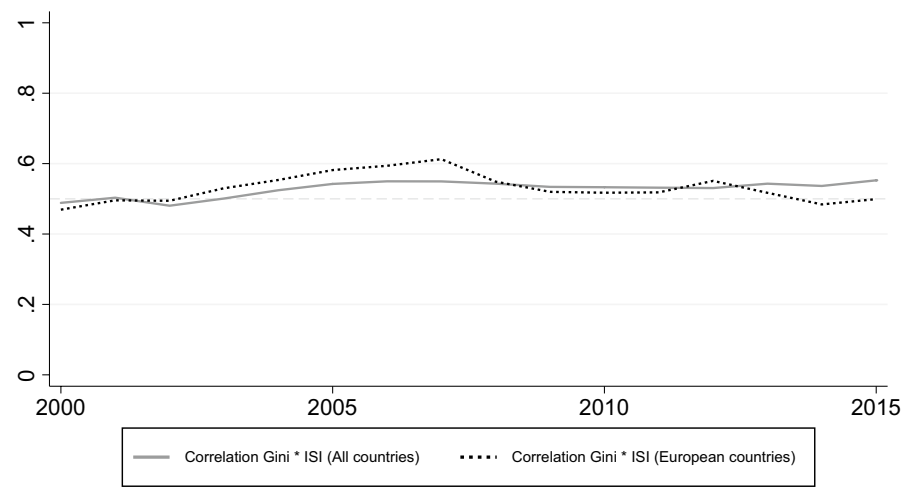

Fig. 4 Correlations of the ISI with income inequality between 2000 and 2015. Note: Pearson's Correlations by year $(\mathrm{N}=40)$. All economic conditions are lagged by 2 years, i.e. Income Inequality 1998-2013 corresponds to Index of Social Ills 2000-2015

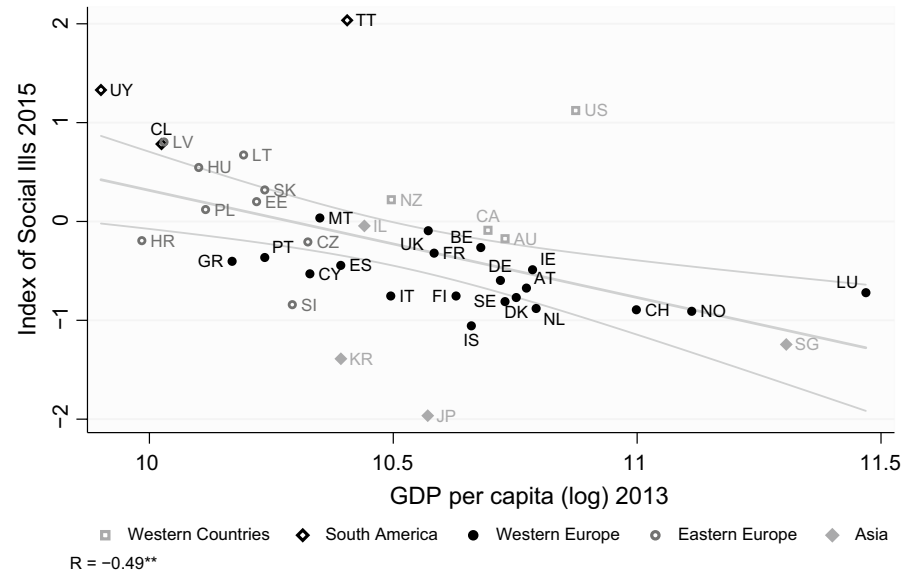

Fig. 5 Relationship between the ISI and economic prosperity. Note: Pearson's Correlations $(\mathrm{N}=40)$. All economic conditions are lagged by 2 years, i.e. economic prosperity 2013 corresponds to Index of Social Ills 2015

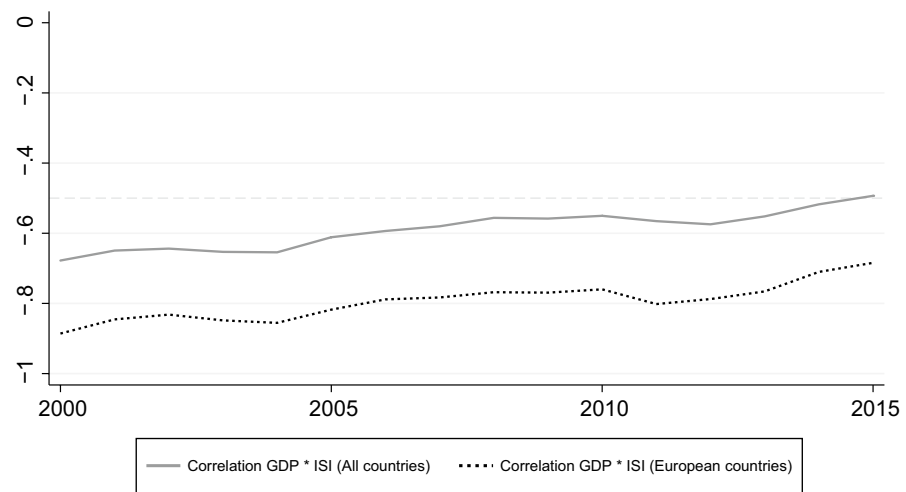

Fig. 6 Correlations of the ISI with economic prosperity between 2000 and 2015. 21 Figure 5 Correlations of the ISI with Economic Prosperity between 2000 and 2015. Note: Pearson's Correlations by year $(\mathrm{N}=40)$. All economic conditions are lagged by 2 years, i.e. economic prosperity 1998-2013 corresponds to Index of Social Ills 2000-2015 
we added to their sample, ten countries experienced levels of social ills above average, and nine below average.

Over time (2000-2015), the number of social ills decreased in almost all countries but three: in Trinidad and Tobago, they slightly increased, and in Uruguay and Malta, the ISI score was virtually unchanged. For all other countries we can record either small (e.g. in Sweden and Israel), considerable (e.g. in the United Kingdom and Poland) or large improvements (e.g. in Slovenia and Estonia). Post-communist countries in particular moved towards fewer social ills, and especially the 'Baltic tigers', first and foremost Estonia.

\subsection{Correlation Analysis}

To provisionally investigate the first two hypotheses, the relationships between the ISI and income inequality and economic prosperity, respectively, are first explored visually in Figs. 3, 4, 5, 6 and then examined cross-sectionally and over time. Figures 3 and 5 show the most up-to-date relationship between the ISI (in 2015) and inequality/prosperity (in 2013, with the lag of 2 years mentioned above). Figures 4 and 6 show the correlation coefficients of the same relationships over the entire time period 2000-2015 year-by-year, for the global sample and the European sub-sample, respectively. ${ }^{9}$

The relevance of income inequality to a society's current level of social ills is evident in Fig. 3. The close relationship $(r=0.55, p<0.001)$ between the Gini coefficient and the ISI in the global sample implies that high inequality countries suffer more from social ills. Some countries fare much better or much worse than their level of inequality alone would suggest, however: for example, Japan, Korea and Singapore do much better regarding social ills, while Slovakia, Hungary, the USA, Uruguay, and Trinidad and Tobago do much worse. This is a hint that other conditions also play a part in generating social ills. Tracking the association in the global sample over the course of 16 years, we find a positive and significant correlation of moderate strength between the Gini coefficient and the ISI in each year (Fig. 4). The strength of the relationship increased slightly from 2000 to 2006 and has stagnated since. In comparison, the association between inequality and social ills among the European countries reached its peak in 2008 (at $\mathrm{r}=0.61, p<0.01$ ) and has since-with the exception of 2013 - decreased slightly below the level of association found in the full sample.

As Fig. 5 indicates, the current level of social ills in the global sample is closely related to a country's economic prosperity, too $(r=-0.49, p<0.01)$. Even among well-off societies, the more prosperous ones suffer less from social ills. Again, some countries deviate considerably from the regression line; two of the Asian countries, South Korea and Japan, as well as Slovenia, do a better job of containing social ills than their level of prosperity alone suggests, whereas the USA, Uruguay, and Trinidad and Tobago appear unable to buy their way out of their social malaise. From a year-by-year perspective (Fig. 6), it becomes evident that in both the global and the European sample, the relationship between prosperity and social ills used to be much stronger in the early 2000s and has since-with the exception of two peaks in 2004 and 2011/12 - constantly decreased. Yet he strength of correlation is still moderate in the full sample $(-0.49, p<0.001)$ and considerable in Europe $(-0.68, p<0.01)$.

${ }^{9}$ For correlation coefficients and p-values by year, see Table 11 in the appendix . 


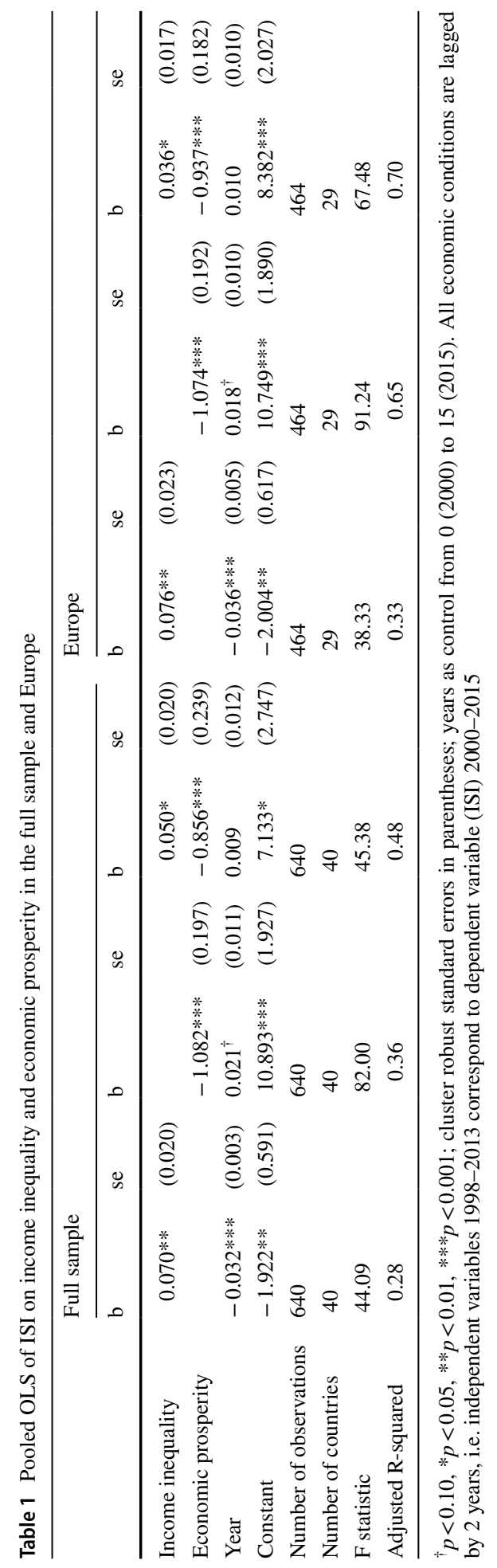


To summarize, income inequality and economic prosperity show relatively constant and significant associations with social ills, findings that provide provisional support for $\mathrm{H} 1$ but not for H2. Finally, while the association between prosperity and social ills is indeed stronger in the culturally more homogenous set of European countries, the relationship between income inequality and social ills is not, providing initial support for $\mathrm{H} 3$.

\subsection{Cross-Sectional Regression Analysis}

As bivariate correlations do not provide conclusive evidence and could hide interrelations among the economic conditions, we move to multivariate modelling. Pooled OLS regression modeling enables us to estimate the effects of the two economic conditions simultaneously while controlling for year-effects. By including observations for 16 years we increase the otherwise small sample size of 40 cases to 640 observations, and are able to investigate the effects of economic conditions cross-sectionally over a period of time instead of relying on the estimates of one single point in time. Table 1 provides the results of the pooled OLS of social ills on income inequality and prosperity for the two sets of countries, global and European. The first model in each panel presents the estimation results for income inequality, the second model those for prosperity, and the third model those for both economic conditions considered together.

Both globally and for Europe, the full models confirm our findings from the bivariate correlations. Income inequality (heightening) as well as economic prosperity (attenuating) are significantly associated with societies' levels of social ills, even when used simultaneously as predictors. These results support H1, but not H2. In the full models, the corrosive effect of income inequality is only slightly stronger, if anything, in the global sample than in the European sub-sample, in line with $\mathrm{H} 3$.

\subsection{Longitudinal Analysis}

Although we now know that less unequal and more prosperous countries are plagued less by social ills, we still do not know what impact, cross-temporally, changes in these conditions have. Fixed effects regression modelling enables us to investigate whether increasing inequality or prosperity lead to changes in the levels of social ills. Two-way fixed effects (TWFE) for countries and years eliminate unobserved country- and timeinvariant heterogeneity-such as cultural characteristics or events such as the financial crisis - that might affect both economic conditions and social ills.

Table 2 provides the results of the TWFE regression of the Social Ills Index on income inequality and economic prosperity, separately and controlled for each other. In the global sample, neither changes in income inequality nor in prosperity exert any influence on social ills. Changes in inequality also do not affect social ills in the European sub-sample; however, there is a significant causal impact from rising prosperity for Europe. When European countries become wealthier, their level of social ills decreases. These results contradict $\mathrm{H} 4$ and thus the inequality hypothesis generally. 


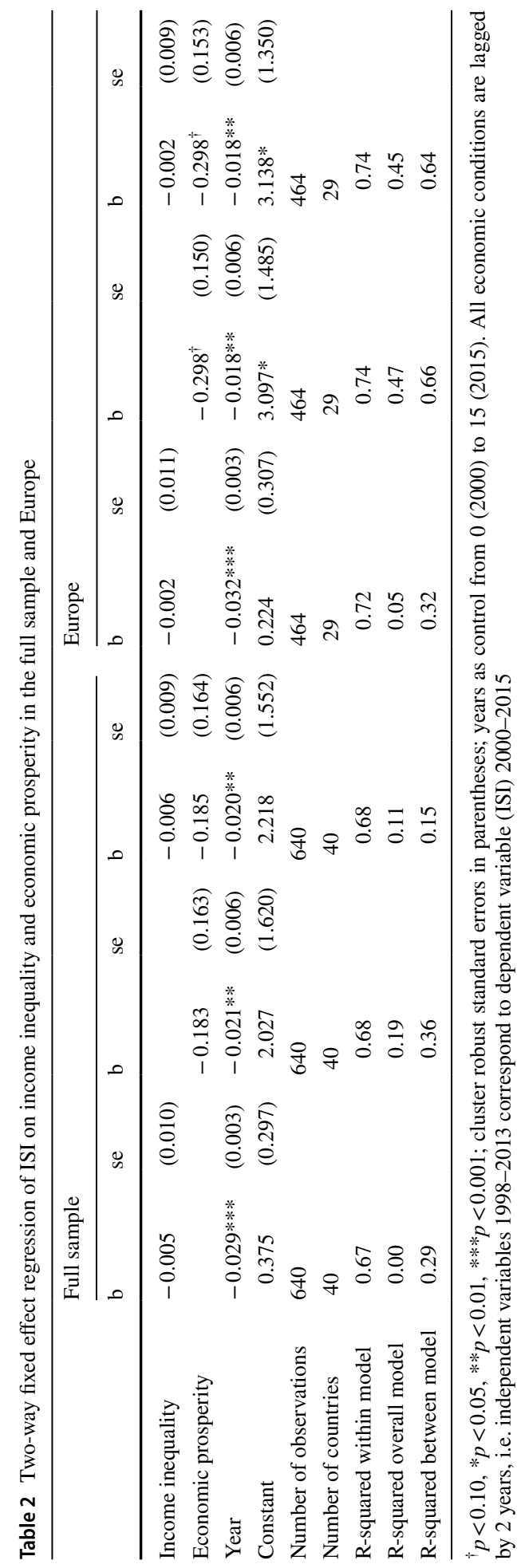




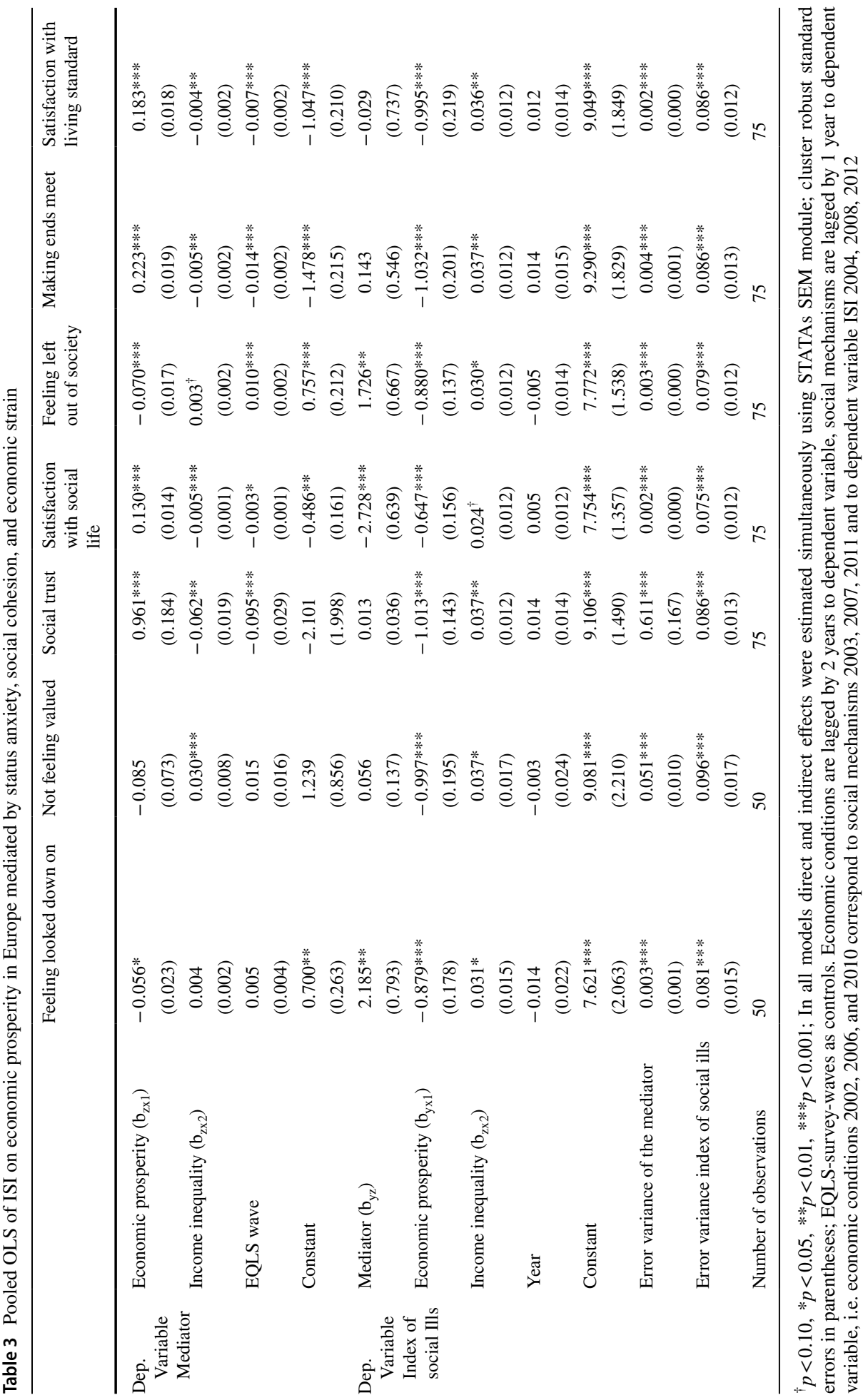


Fig. 7 Mediation results
(1) Indirect effect: $b=-0.122 *(0.060) .12,2 \%$ of total effect.

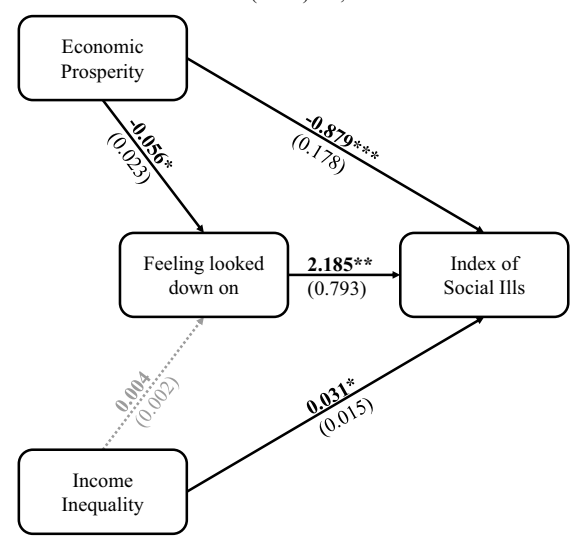

Indirect effect: No significant indirect effect.

(2) Indirect effect: $\mathrm{b}=-0.354 * * *(0.086) .35,4 \%$ of total effect.

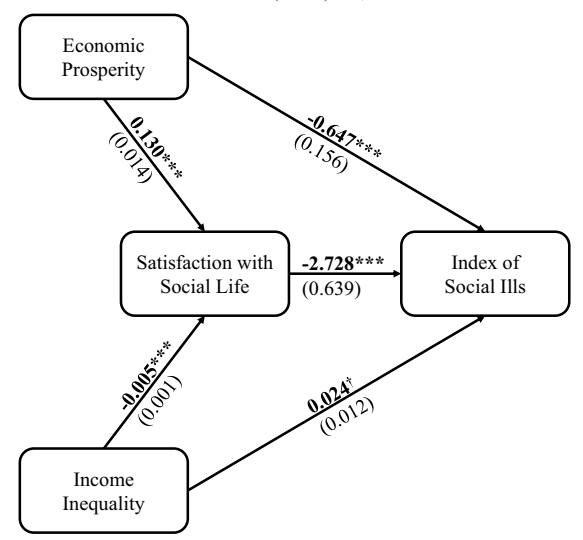

Indirect effect: $b=-0.013 * *(0.004) .34 .3 \%$ of total effect.

(3) Indirect effect: $\mathrm{b}=-0.121 *(0.050) .12,1 \%$ of total effect.

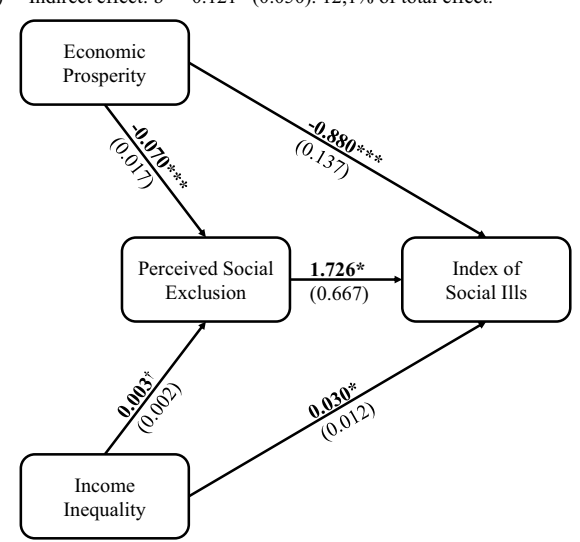

Indirect effect: No significant indirect effect. 


\subsection{Mediation Analysis}

In the third and final step of our analysis we turn to the mechanism(s) converting adverse economic conditions into social ills. The subsequent mediation analysis builds on the insights gained from the results presented above, and includes, in addition to the mediators, income inequality and economic prosperity as determinants of social ills in the cross-sectional analysis, but only economic prosperity in the longitudinal analysis. We run separate analyses for each of the variables used to operationalize the various mechanisms, estimating structural equation models controlled for years for the crosssectional analysis and two separate fixed effects models for the longitudinal analysis. Please recall that the mediation analysis is confined to our 25 European countries participating in the EQLS.

\subsubsection{Mediation: The Cross-Sectional Perspective}

Table 3 provides the results of the structural equation models for each mediator. The upper part reports the effects of economic prosperity $\left(b_{\mathrm{zx} 1}\right)$ and income inequality $\left(\mathrm{b}_{\mathrm{zx} 2}\right)$ on the respective mediator, while the lower part presents the effect of the economic conditions $\left(b_{\mathrm{yx} 1}, b_{\mathrm{yx} 2}\right)$ and of the mediator $\left(\mathrm{b}_{\mathrm{yz}}\right)$ on the Index of Social Ills.

We find evidence that three of the indicators mediate between the economic situation of a country and its level of social ills: being looked down on (tapping status anxiety), and satisfaction with one's social life and feeling left out of society (both representing social cohesion). The paths of these three mechanisms are illustrated in Fig. 7.

Starting with the status anxiety item (Panel 1), we find that, on average, people feel less looked down on in more affluent nations, but not in more equal countries. In turn, these widespread feelings of inferiority in a population are associated with more social ills. Both income inequality and economic prosperity are still directly associated with social ills, while roughly $12 \%$ of the effect of prosperity is mediated through the prevalence of inferiority. For the first 'successful' cohesion item (Fig. 7, Panel 2), inequality is negatively, and prosperity positively, associated with population-average satisfaction with social life. In turn, we find fewer social ills in countries with a socially satisfied population. Again, the direct effects of the two economic conditions remain significant when the mediator is introduced, but some $35 \%$ of the effect of both economic conditions is mediated through satisfaction with social life. Finally, for the second 'successful' cohesion item (Fig. 7, Panel 3 ), perceived exclusion is higher in more unequal and lower in more affluent countries; and in turn, higher rates of perceived exclusion are associated with higher levels of social ills. Only the indirect effect of prosperity is significant, however: some $12 \%$ of it is mediated through social exclusion. Again, the direct effects of the economic conditions remain significant.

In summary, from a cross-sectional perspective only satisfaction with social life (social cohesion) partially mediates the effect of inequality on the level of social ills (lending partial support for H6), while status anxiety (contradicting H5) and economic strain (contradicting H7) do not mediate the detrimental effects of inequality. In contrast, two characteristics of social cohesion and aggregate status anxiety (but again not economic strain) partially mediate the social ills-attenuating effect of prosperity. 


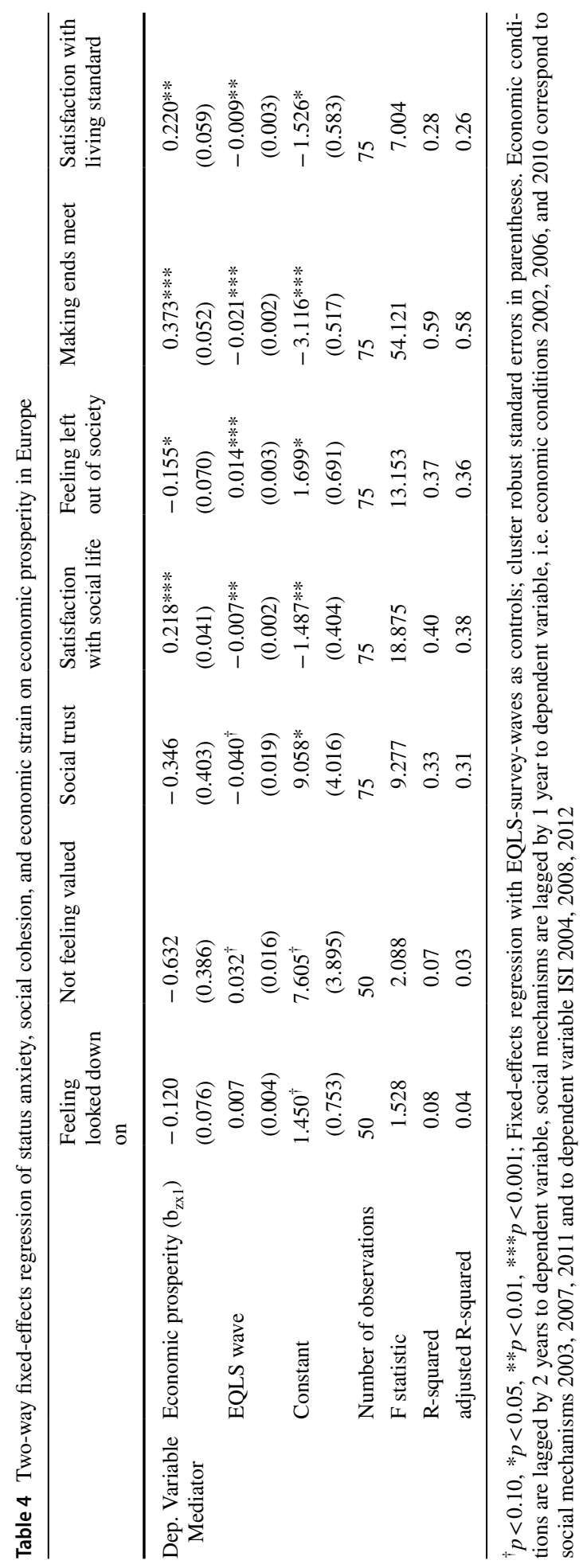




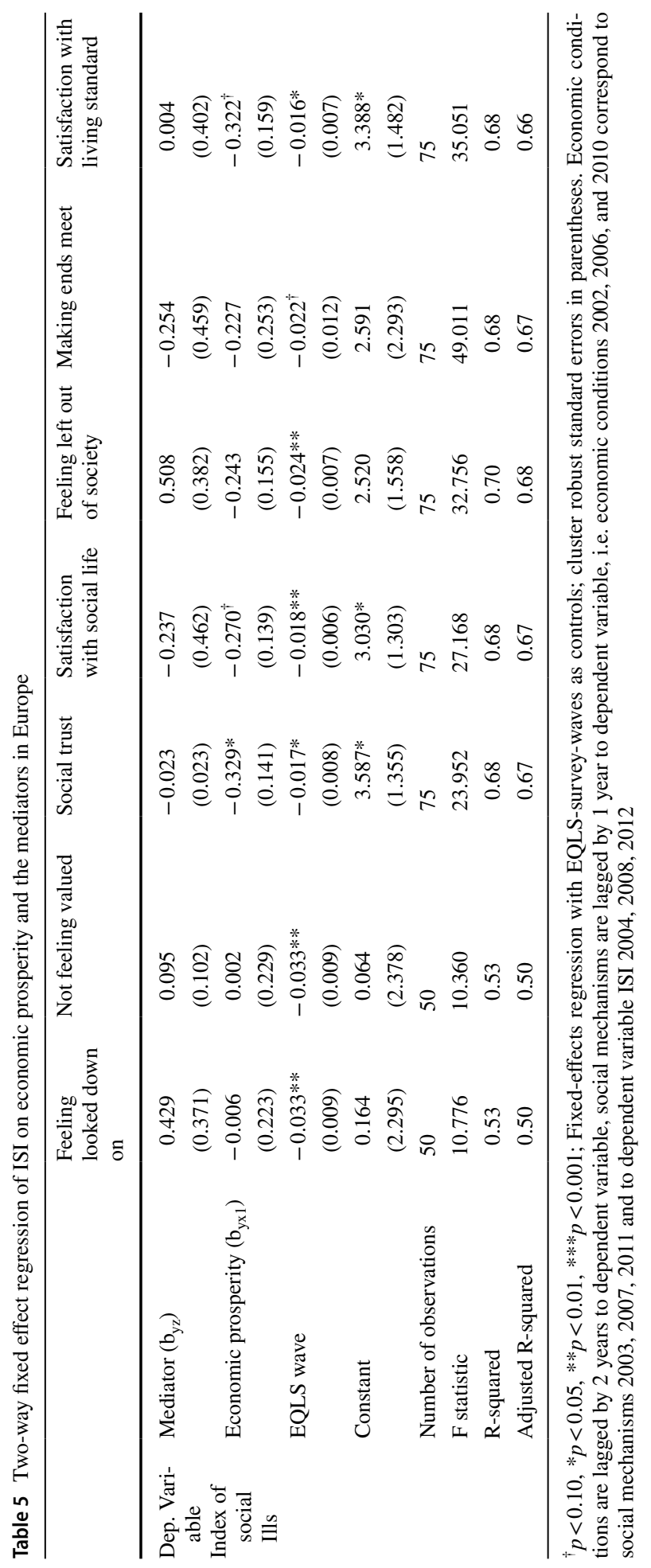




\subsubsection{Mediation: The Longitudinal Perspective}

Informed by the outcomes of the fixed-effect regression models presented above, a longitudinal mediation analysis is performed for economic prosperity only. Table 4 provides the results of the TWFE regressions of the mediators on economic prosperity $\left(b_{\mathrm{zx} 1}\right)$, and Table 5 shows the effects of prosperity $\left(b_{\mathrm{yx} 1}\right)$ and the mediators $\left(b_{\mathrm{yz}}\right)$ on the social ills. Four of the seven mediator variables are significantly affected by changes in prosperity: growing wealth increases population-average satisfaction with social life (thus strengthening social cohesion), decreases feelings of social exclusion (thus strengthening social cohesion), and increases both the ability to make ends meet and satisfaction with the standard of living (thus reducing economic strain). None of the mediators, however, exert a significant effect on the change in social ills once economic prosperity is introduced (Table 5) ${ }^{10}$ From a longitudinal perspective we thus find no evidence that the decrease of social ills induced by growing prosperity is mediated by any of the quality-of-life mechanisms we examined.

Ultimately, the relative positions that rich countries hold regarding their levels of income inequality and economic prosperity matter for their level of social ills relative to other countries (the cross-sectional perspective). This is a robust finding for both our global sample and the European sub-sample. Within one country (the longitudinal perspective), however, an improvement in income distribution over time does not lead to fewer social ills, whereas rising prosperity does-but only in Europe, not in the global sample. As to social mechanisms, only people's satisfaction with social life (social cohesion) mediates between both inequality and prosperity, when comparing countries cross-sectionally. Longitudinally, none of the mediators examined help to explain why rising prosperity reduces the number of social ills.

\section{Discussion and Conclusion}

By examining the impact of economic conditions on a broad range of social ills for 40 rich countries for the period 2000-2015, this study represents the most up-to-date and comprehensive examination of the famous inequality hypothesis. To our knowledge, this is also the first aggregate-level study in which a larger number of potential mediators between economic conditions and social ills has been put to an empirical test. Descriptively, while the ranking of countries according to their number of social ills largely matches that presented in The Spirit Level, our finding that social ills have decreased over time in all but two countries is a genuinely new finding that contradicts the widely accepted diagnose of social malaise in the developed world (Eckersley 2012; Elchardus and De Keere 2013). While some of our results provide partial support for the inequality hypothesis, others contradict it. We begin our discussion with the supporting evidence, which stems exclusively from the cross-sectional analysis.

The first confirmatory finding is that cross-sectionally the scale of income inequality is positively associated-year by year-with social ills, an association that holds when economic prosperity is considered at the same time (confirming H1). This association is

\footnotetext{
${ }_{10}$ When estimating the effects of the mediators on ISI without controlling for economic prosperity, social exclusion exerts a positive effect, and the ability to make ends meet a negative effect (see Table 12 in the appendix).
} 
found in our two sets of rich countries, the global (full) sample, which is culturally more diverse, and the subset of European countries (confirming H3). There thus seems to be no need to confine the inequality hypothesis to the Western world. In light of the criticism that Wilkinson and Pickett especially received for disregarding cultural peculiarities (Saunders and Evans 2010; Snowdon 2010), this is a most relevant finding.

A second and at least partly theory-confirming finding concerns potential mediators. Our cross-sectional results lend some support, first of all, to the idea that status anxiety mediates between economic conditions and social ills. Two qualifications, however, are essential. While average levels of status anxiety are systematically higher in less affluent countries, they are not higher in more unequal ones, as The Spirit Level presumes. Secondly, our cross-sectional finding that the characteristics of social cohesion perform better as mediators suggests that it is the erosion of social life more generally which evokes health and social problems, not status anxiety specifically. Interestingly, this conclusion resonates well with the thrust of Wilkinson's $(1996,1999)$ older works.

As regards the findings that challenge the inequality hypothesis and the spirit level theory, most importantly, changing income inequality does not cause changes in the number of social ills (disconfirming H4). Our study thus joins those that find a link between inequality and social ills cross-sectionally, but not longitudinally (e.g. Beckfield 2004; Leigh and Jencks 2007; Avendano 2012; Hu et al. 2015). Our results further indicate that economic prosperity is related to lower social ills-cross-sectionally in both subsets of rich nations, and longitudinally in Europe, in both cases while simultaneously considering the income distribution. This questions the exclusive focus on inequality that many scholars advocate. The positive impact of prosperity on societies is already observable at the beginning of the 2000s according to our data; and so it was not a new phenomenon that appeared after The Spirit Level was published. Seen in conjunction with the mounting evidence that individual quality of life is also better in richer countries (e.g., Hagerty and Veenhoven 2003; Deaton 2008; Delhey and Steckermeier 2016), it appears premature to declare economic resources ineffective for making lives and societies better, and even more so, as in the study at hand increases in economic prosperity over time decrease social ills, at least in Europe. In our data, the causal effect on social ills is actually exerted by economic prosperity, not by changes in the income distribution. Still, we do not want to gloss over the finding that in the European sub-sample the cross-sectional association between economic prosperity and social ills became weaker in later years of the period studied. This might mean that some rich societies are experiencing diminishing returns from economic resources, but still have positive returns-in particular in Europe-so "wealthier is healthier" (Biggs et al. 2010) is still a valid slogan for contemporary rich societies.

The mediation analysis could only be performed for Europe. Here, a genuinely new finding is that the same mechanisms that mediate in cross-sectional analysis between inequality and social ills also mediate between economic prosperity and social ills, namely satisfaction with social life and experienced social exclusion (largely in support of the cross-sectional part of H6); and further, that the mechanism prominently proposed by the spirit level theory-feelings of inferiority-only mediates the attenuating effect of economic prosperity. This suggests that prosperity exerts its positive effect on social ills by improving the social climate within societies (cf. Welzel 2013; Delhey and Dragolov 2016). Nevertheless, the longitudinal mediation analysis could not ultimately clarify the experienced quality-of-life mechanism through which economic prosperity has an effect on social ills. Future research, ideally based on larger case numbers, might yield more conclusive results on this issue.

Our results for economic prosperity raise the important question of why we unearthed a robust prosperity-social ills nexus when Wilkinson and Pickett did not. Re-running our analysis 
for the set of 21 countries from The Spirit Level, we find two explanations: country selection and methods. Indeed, there is no significant correlation between economic prosperity and our ISI index for the 21 countries in any of the years 2000-2015. In other words, it is Wilkinson and Pickett's - disputable — compilation of countries which produces a non-correlation. Furthermore, when estimating pooled OLS regressions of ISI on inequality and prosperity for their 21 countries over the full period of 16 years, there is a robust social ills attenuating effect of prosperity, entirely in line with our results, but contrary to Wilkinson and Pickett. This demonstrates how unadvisable it is to draw conclusions based on zero-order correlations alone.

A limitation of our study is that the mediation analysis could only be performed for Europe. European societies are in the vanguard of value change toward self-expression values (Inglehart and Welzel 2005; Welzel 2013). Provided this peculiarity rubs off on the social production functions of these societies, we cannot rule out that the focus on Europe in the mediation analysis overemphasizes the role of social mediators and underemphasizes the role of material ones, such as economic strain. Moreover, a multi-level framework could be applied to the best-performing mechanisms from our analysis to determine whether they imply contextual effects of inequality and prosperity, or rather composition effects (for status anxiety, see, for example, Whelan and Layte 2014). Further research is also needed to explore potential cultural conditions that breed or prevent social ills. Although we have established that the impact of income inequality is not weaker in the culturally diverse global sample, it is still conceivable that cultural forces play their part in the generation of health and social problems.

In conclusion, while from a cross-sectional perspective the inequality hypothesis seems accurate but one-sided, in a longitudinal perspective it appears to be wrong. This news might be hard to digest for those who assume that creating a 'better' society is, definitely and primarily, a matter of income redistribution. For policymakers, our study instead suggests that economic prosperity should be prioritized over income redistribution as an instrument to achieving a less problem-ridden society. Naturally, tackling inequalities might still be of paramount importance for achieving other valuable goals, such as to enhance social justice.

Acknowledgements We are grateful to Philipp Kadelke for his support with data collection and initial analyses. We also would like to thank the two anonymous reviewers for their valuable suggestions and comments. The author(s) disclosed receipt of the following financial support for the research, authorship, and/ or publication of this article: This research is part of the project 'Inequality, Status Anxiety, and Quality of Life. An Examination and Extension of the Spirit Level Theory for Europe' (grant number: DE 1892/3-1), which is supported by the German Research Foundation (DFG).

Open Access This article is licensed under a Creative Commons Attribution 4.0 International License, which permits use, sharing, adaptation, distribution and reproduction in any medium or format, as long as you give appropriate credit to the original author(s) and the source, provide a link to the Creative Commons licence, and indicate if changes were made. The images or other third party material in this article are included in the article's Creative Commons licence, unless indicated otherwise in a credit line to the material. If material is not included in the article's Creative Commons licence and your intended use is not permitted by statutory regulation or exceeds the permitted use, you will need to obtain permission directly from the copyright holder. To view a copy of this licence, visit http://creativecommons.org/licenses/by/4.0/.

\section{Appendix}

See Tables 6, 7, 8, 9, 10, 11 and 12 . 
Table 6 Selection process of rich countries by theoretical considerations and data availability

Starting point: High income in 2015 and at least upper middle income 2000-2015

$=70$ countries

- Theoretical consideration (1): Dropped because not upper middle or high income, 2000-2015

British Virgin Islands, Curacao, Gibraltar, Nauru, Saint Maarten (Dutch part), St. Martin (French part), Turks and Caicos Islands

- Theoretical consideration (2): Dropped because tax haven

Andorra, Antigua and Barbuda, Aruba, Bahamas, Bahrain, Bermuda, Cayman Islands, Lichtenstein, Monaco, St. Kitts and Nevis

- Theoretical consideration (3): Dropped because less than 300.000 inhabitants

Barbados, Channel Island, Faeroe Islands, French Polynesia, Greenland, Guam, Isle of Man, New Caledonia, Northern Mariana Islands, San Marino, Seychelles, Virgin Islands (U.S.)

- Missing data (1): World Bank data

Taiwan

Missing data (2): WHO data on BMI

Puerto Rico

- Missing data (3): Gini data

Brunei Darussalam, Kuwait, Macao SAR (China), Oman, Qatar, Saudi Arabia, United Arab Emirates

Final set of 40 countries (full sample):

Australia, Austria, Belgium, Canada, Chile, Croatia, Cyprus, Czech Republic, Denmark, Estonia, Finland, France, Germany, Greece, Hungary, Iceland, Ireland, Israel, Italy, Japan, Korea (Rep.), Latvia, Lithuania, Luxembourg, Malta, Netherlands, New Zealand, Norway, Poland, Portugal, Singapore, Slovak Republic, Slovenia, Spain, Sweden, Switzerland, Trinidad and Tobago, United Kingdom, United States, Uruguay 


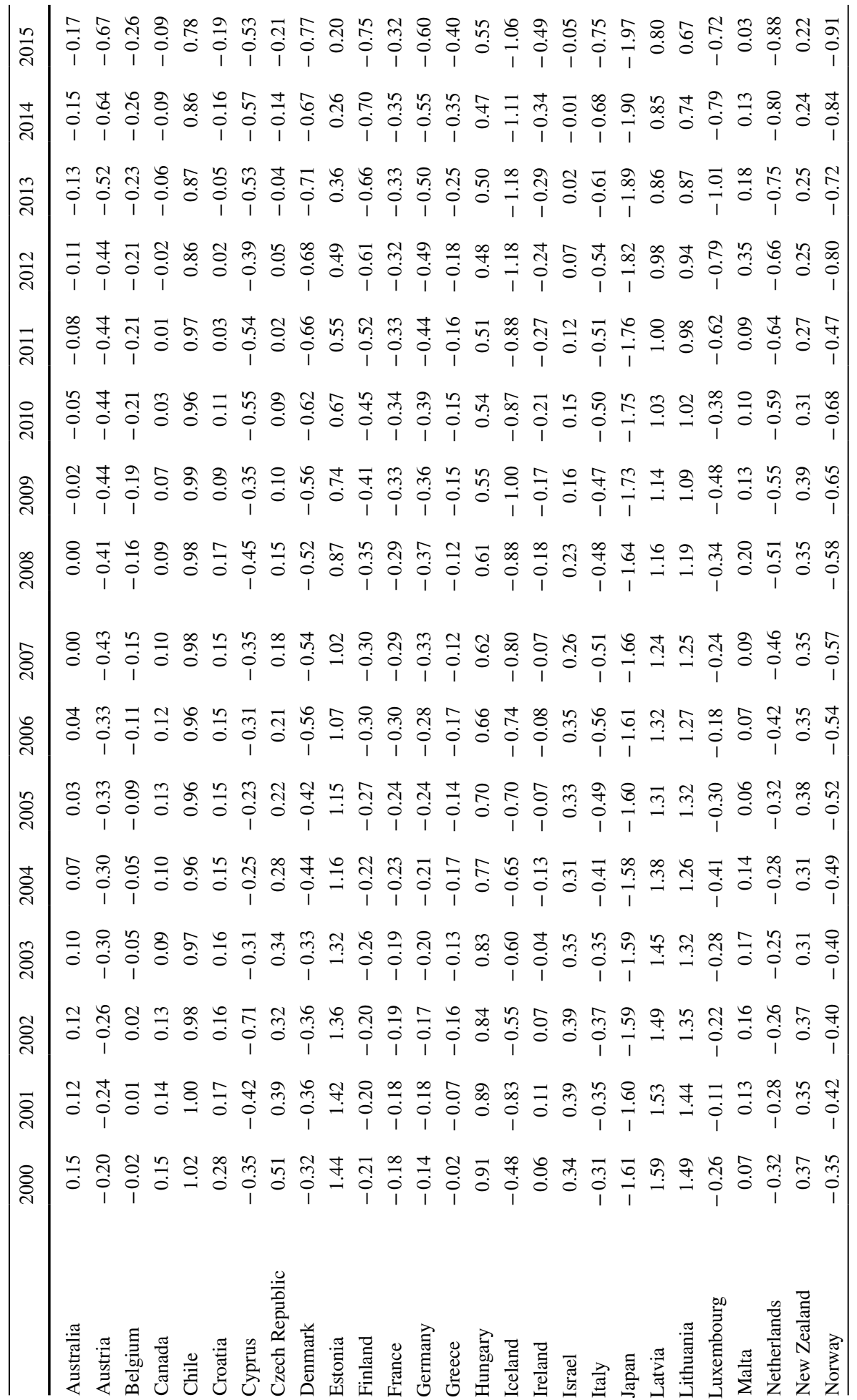




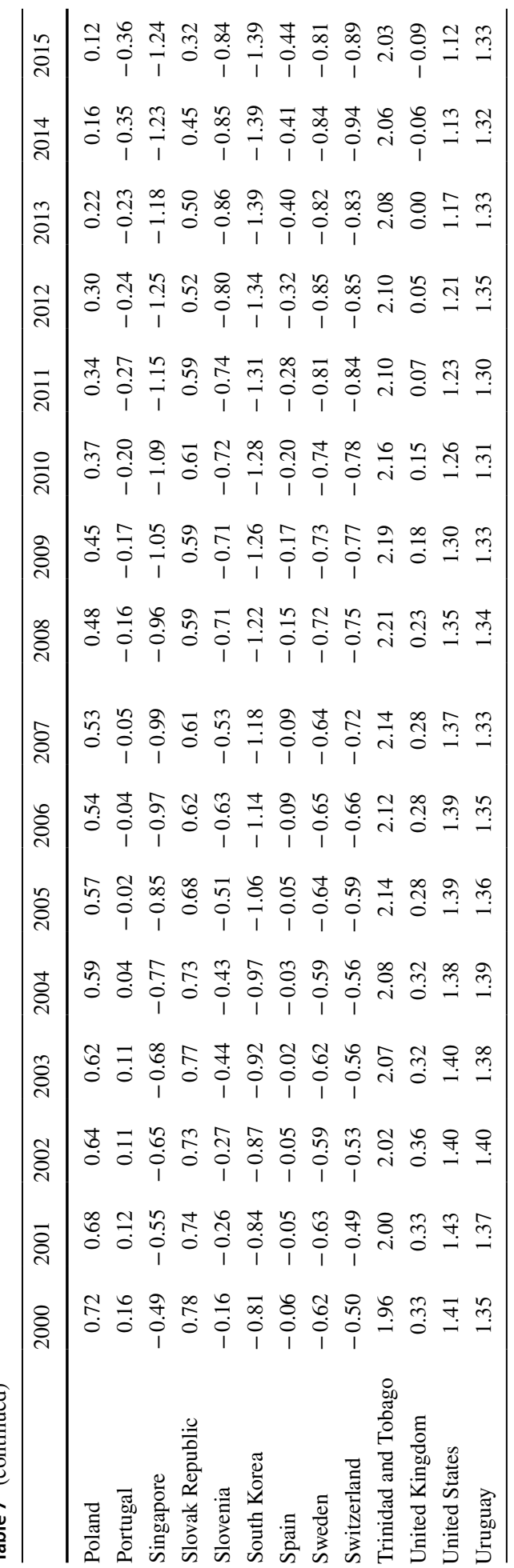




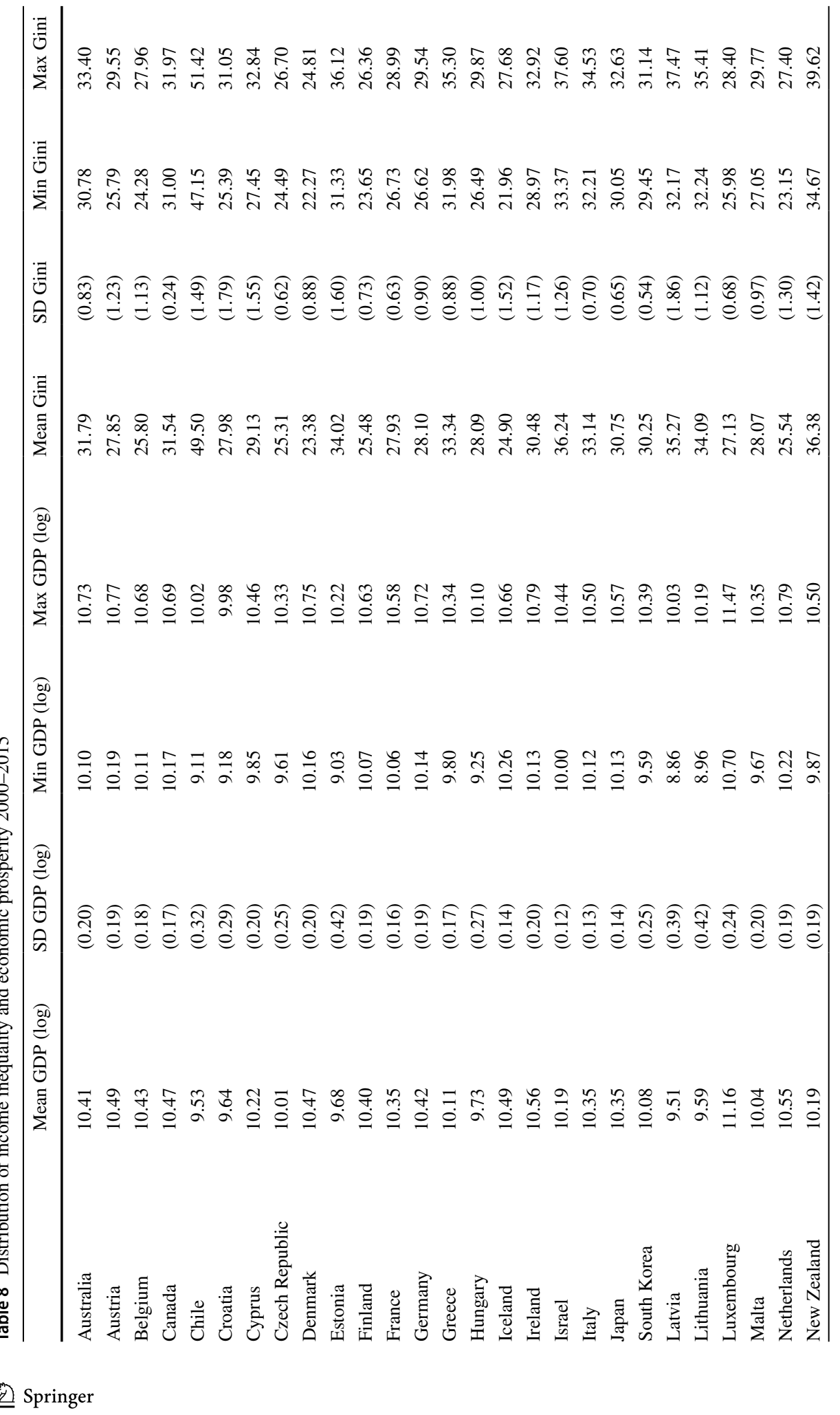




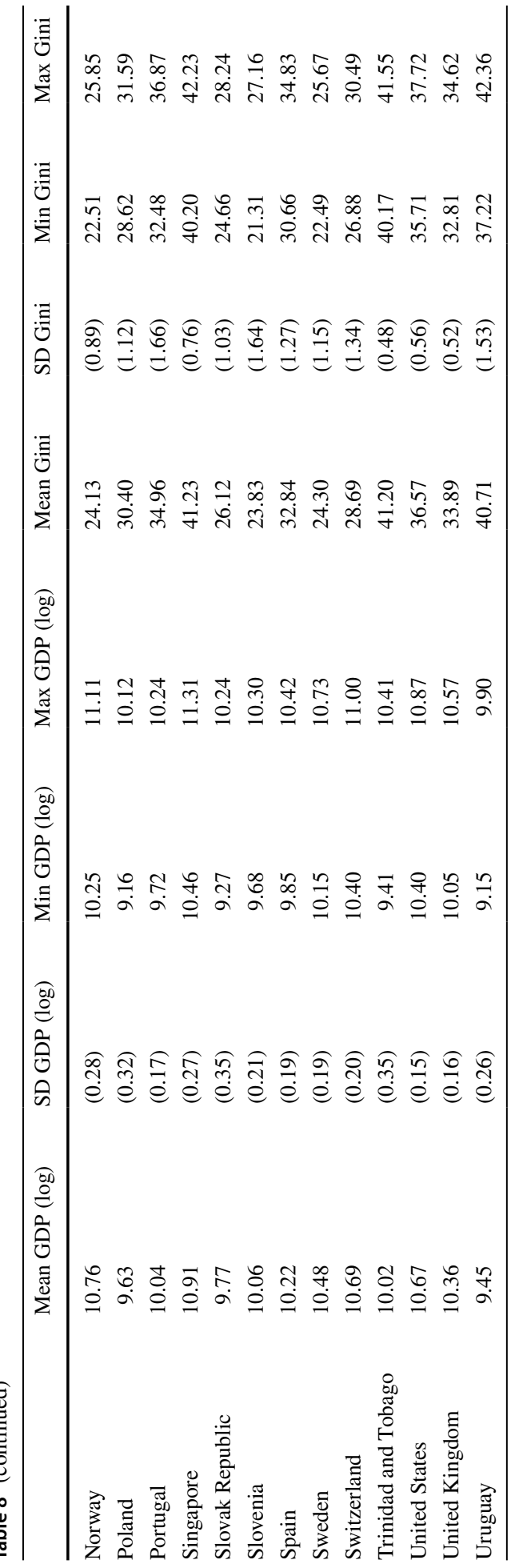


Table 9 EQLS respondents and response rates by wave

\begin{tabular}{|c|c|c|c|}
\hline & $\begin{array}{l}\text { Respondents } \\
2003\end{array}$ & $\begin{array}{l}\text { Respondents } \\
2007\end{array}$ & $\begin{array}{l}\text { Respondents } \\
2011\end{array}$ \\
\hline Austria & 1007 & 1043 & 1032 \\
\hline Belgium & 1005 & 1010 & 1013 \\
\hline Cyprus & 598 & 1003 & 1006 \\
\hline Czech Republic & 995 & 1227 & 1012 \\
\hline Germany & 1052 & 2008 & 3055 \\
\hline Denmark & 999 & 1004 & 1024 \\
\hline Estonia & 591 & 1023 & 1002 \\
\hline Greece & 1002 & 1000 & 1004 \\
\hline Spain & 1005 & 1015 & 1512 \\
\hline Finland & 997 & 1002 & 1020 \\
\hline France & 1033 & 1537 & 2270 \\
\hline Hungary & 1001 & 1000 & 1024 \\
\hline Ireland & 990 & 1000 & 1051 \\
\hline Italy & 1004 & 1516 & 2250 \\
\hline Lithuania & 1001 & 1004 & 1134 \\
\hline Luxembourg & 605 & 1004 & 1005 \\
\hline Latvia & 1004 & 1002 & 1009 \\
\hline Malta & 603 & 1000 & 1001 \\
\hline Netherlands & 1050 & 1011 & 1008 \\
\hline Poland & 1000 & 1500 & 2262 \\
\hline Portugal & 998 & 1000 & 1013 \\
\hline Sweden & 1000 & 1017 & 1007 \\
\hline Slovenia & 601 & 1035 & 1008 \\
\hline Slovakia & 1071 & 1128 & 1000 \\
\hline UK & 1012 & 1507 & 2252 \\
\hline Response Rate & $58 \%$ & $56 \%$ & $41 \%$ \\
\hline
\end{tabular}




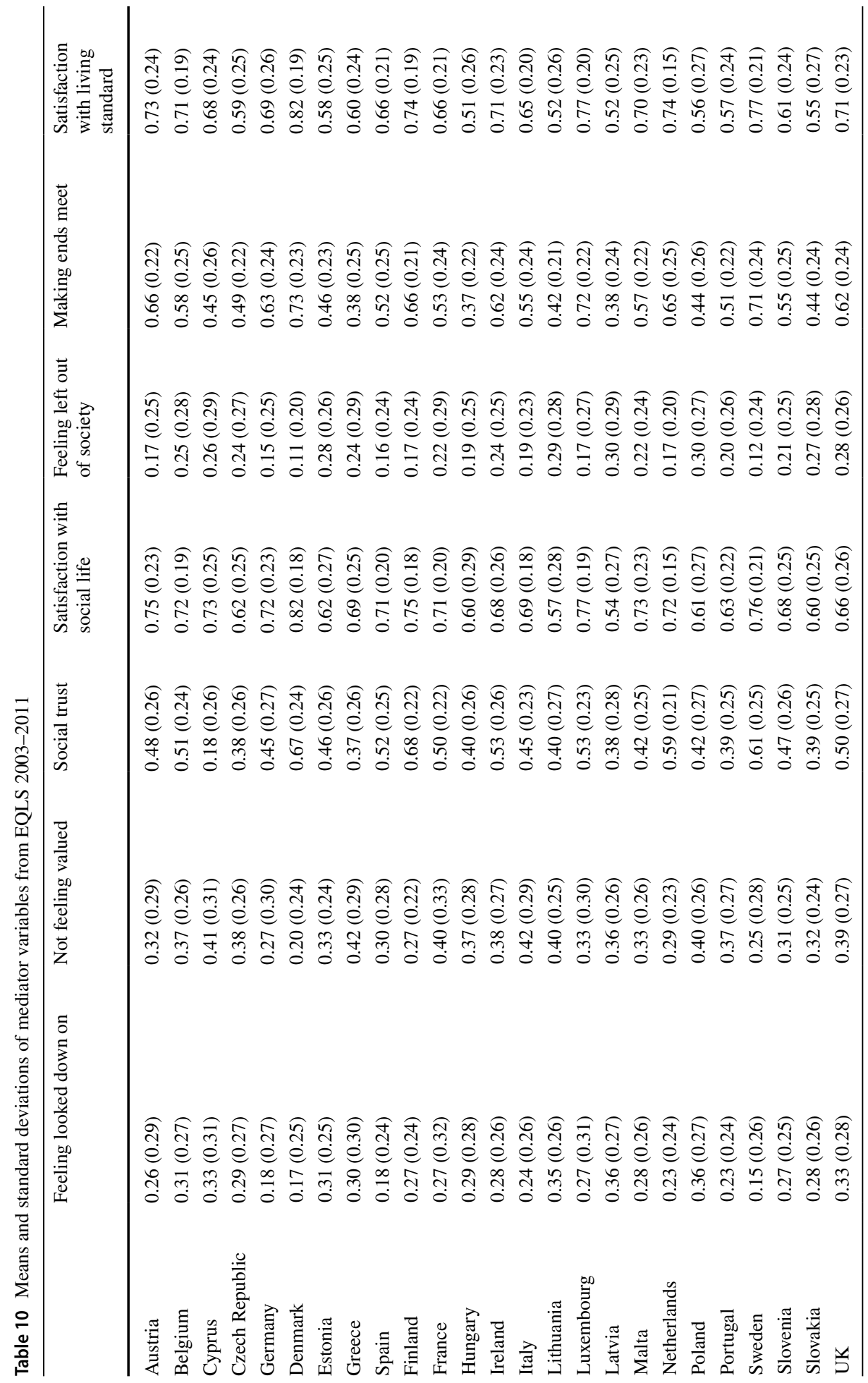


Table 11 Correlation of Ginicoefficient, GDP p.c. with index of social ills in all countries and European countries

\begin{tabular}{|c|c|c|c|c|c|}
\hline & \multirow[t]{2}{*}{ Year } & \multicolumn{2}{|c|}{$\begin{array}{l}\text { All countries } \\
(\mathrm{N}=40)\end{array}$} & \multicolumn{2}{|c|}{$\begin{array}{l}\text { European Countries } \\
(\mathrm{N}=29)\end{array}$} \\
\hline & & Pearson's r & $p$ & Pearson's $r$ & $p$ \\
\hline \multirow[t]{16}{*}{ GDP pc PPP $(\log )$} & 2000 & -0.6777 & 0.0000 & -0.8858 & 0.0000 \\
\hline & 2001 & -0.6493 & 0.0000 & -0.8455 & 0.0000 \\
\hline & 2002 & -0.6438 & 0.0000 & -0.8319 & 0.0000 \\
\hline & 2003 & -0.6531 & 0.0000 & -0.8483 & 0.0000 \\
\hline & 2004 & -0.6543 & 0.0000 & -0.8553 & 0.0000 \\
\hline & 2005 & -0.6113 & 0.0000 & -0.8177 & 0.0000 \\
\hline & 2006 & -0.5935 & 0.0001 & -0.7884 & 0.0000 \\
\hline & 2007 & -0.5801 & 0.0001 & -0.7830 & 0.0000 \\
\hline & 2008 & -0.5561 & 0.0002 & -0.7680 & 0.0000 \\
\hline & 2009 & -0.5582 & 0.0002 & -0.7692 & 0.0000 \\
\hline & 2010 & -0.5503 & 0.0002 & -0.7599 & 0.0000 \\
\hline & 2011 & -0.5655 & 0.0001 & -0.8018 & 0.0000 \\
\hline & 2012 & -0.5745 & 0.0001 & -0.7875 & 0.0000 \\
\hline & 2013 & -0.5519 & 0.0002 & -0.7658 & 0.0000 \\
\hline & 2014 & -0.5175 & 0.0006 & -0.7102 & 0.0000 \\
\hline & 2015 & -0.4933 & 0.0012 & -0.6843 & 0.0000 \\
\hline \multirow[t]{16}{*}{ Gini-coefficient } & 2000 & 0.4885 & 0.0014 & 0.4256 & 0.0102 \\
\hline & 2001 & 0.5032 & 0.0009 & 0.4693 & 0.0062 \\
\hline & 2002 & 0.4805 & 0.0017 & 0.4958 & 0.0064 \\
\hline & 2003 & 0.5009 & 0.0010 & 0.4945 & 0.0031 \\
\hline & 2004 & 0.5244 & 0.0005 & 0.5300 & 0.0018 \\
\hline & 2005 & 0.5423 & 0.0003 & 0.5536 & 0.0009 \\
\hline & 2006 & 0.5497 & 0.0002 & 0.5817 & 0.0007 \\
\hline & 2007 & 0.5495 & 0.0002 & 0.5938 & 0.0004 \\
\hline & 2008 & 0.5431 & 0.0003 & 0.6126 & 0.0021 \\
\hline & 2009 & 0.5339 & 0.0004 & 0.5488 & 0.0039 \\
\hline & 2010 & 0.5330 & 0.0004 & 0.5198 & 0.0041 \\
\hline & 2011 & 0.5316 & 0.0004 & 0.5173 & 0.0040 \\
\hline & 2012 & 0.5306 & 0.0004 & 0.5183 & 0.0020 \\
\hline & 2013 & 0.5431 & 0.0003 & 0.5510 & 0.0041 \\
\hline & 2014 & 0.5366 & 0.0004 & 0.5171 & 0.0078 \\
\hline & 2015 & 0.5526 & 0.0002 & 0.4840 & 0.0058 \\
\hline
\end{tabular}




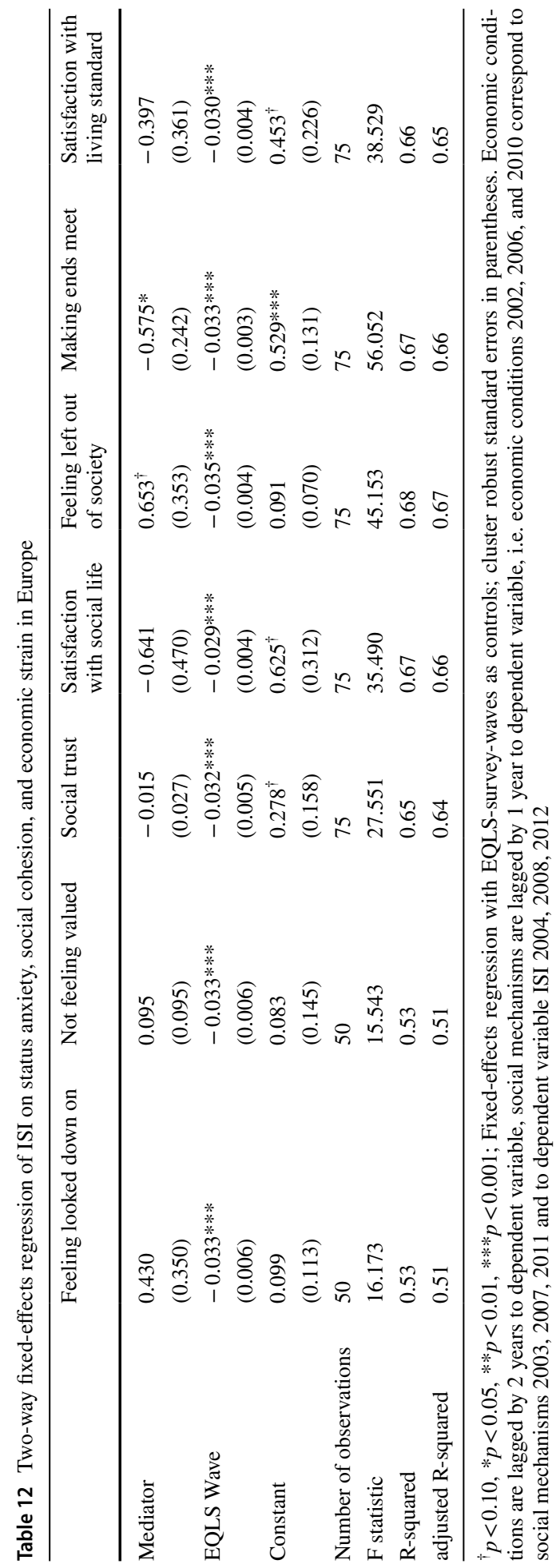




\section{Data Sources}

European Foundation for the Improvement of Living and Working Conditions. (2014) European Quality of Life Survey Integrated Data File, 2003-2012. [data collection]. 2nd Edition. UK Data Service. SN: 7348, http://doi.org/10.5255/UKDA-SN-7348-2.

Solt, Frederick. (2016) The standardized world income inequality database, Social Science Quarterly, 97(5), 1267-1281. [Data file, SWIID] Retrieved from https://dataverse. harvard.edu/dataset.xhtml?persistentId=hdl:1902.1/11992. Last accessed 10 August 2017.

The World Bank, World Development Indicators (2017) Adolescent fertility rate (births per 1000 women ages 15-19), [Data file, Code: SP.ADO.TFRT]. Retrieved from data. worldbank.org/indicator/SP.ADO.TFRT. Last accessed 10 August 2017.

The World Bank, World Development Indicators (2017) GDP per capita, PPP (current international \$), [Data file, Code: NY.GDP.PCAP.PP.CD]. Retrieved from data.worldbank. org/indicator/NY.GDP.PCAP.PP.CD. Last accessed 10 August 2017.

The World Bank, World Development Indicators (2017) GNI per capita in US\$ (Atlas methodology), [Data file, OGHIST]. Retrieved from siteresources.worldbank.org/DATASTATISTICS/Resources/OGHIST.xls. Last accessed 20 December 2017.

The World Bank, World Development Indicators (2017) Intentional homicides (per 100,000 people), [Data file, Code: VC.IHR.PSRC.P5]. Retrieved from data.worldbank.org/ indicator/VC.IHR.PSRC.P5. Last accessed 10 August 2017.

The World Bank, World Development Indicators (2017) Life expectancy at birth, total (years), [Data file, Code: SP.DYN.LE00.IN]. Retrieved from data.worldbank.org/indicator/ SP.DYN.LE00.IN. Last accessed 10 August 2017.

The World Bank, World Development Indicators (2017) Mortality rate, infant (per 1000 live births), [Data file, Code: SP.DYN.IMRT.IN]. Retrieved from data.worldbank.org/indicator/SP.DYN.IMRT.IN. Last accessed 10 August 2017.

The World Bank, World Development Indicators (2017) Unemployment, total (\% of total labor force) (modeled ILO estimate), [Data file, Code: SL.UEM.TOTL.ZS]. Retrieved from data.worldbank.org/indicator/SL.UEM.TOTL.ZS. Last accessed 10 August 2017.

World Health Organization (2017) Global Health Observatory Data Repository: Obesity (body mass index $\geq 30$ ), age-standardized (\%) Estimates by country, [Data file] Retrieved from http://apps. who.int/gho/data/node.main.A900A?lang=en. Last accessed 10 August 2017.

World Prison Brief, Institute for Criminal Policy Research (2017) World Prison Brief data by country, [Data file] Retrieved from http://www.prisonstudies.org/world-priso n-brief-data. Last accessed 10 August 2017.

\section{References}

Agnew, R., \& White, H. R. (1992). An empirical test of general strain theory. Criminology, 30(4), 475-500. https://doi.org/10.1111/j.1745-9125.1992.tb01113.x.

Avendano, M. (2012). Correlation or causation? Income inequality and infant mortality in fixed effects models in the period 1960-2008 in 34 OECD countries. Social Science and Medicine, 75(4), 754-760.

Babones, S. J. (2008). Income inequality and population health: Correlation and causality. Social Science and Medicine, 66(7), 1614-1626. https://doi.org/10.1016/j.socscimed.2007.12.012.

Beckfield, J. (2004). Does income inequality harm health? New cross-national evidence. Journal of Health and Social Behavior, 45(3), 231-248.

Ben-Shlomo, Y., White, I. R., \& Marmot, M. (1996). Does the variation in the socioeconomic characteristics of an area affect mortality? British Medical Journal, 312(7037), 1013-1014. 
Biggs, B., King, L., Basu, S., \& Stuckler, D. (2010). Is wealthier always healthier? The impact of national income level, inequality, and poverty on public health in Latin America. Social Science and Medicine, 71(2), 266-273. https://doi.org/10.1016/j.socscimed.2010.04.002.

Böhnke, P. (2004). Perceptions of social integration and exclusion in an enlarged Europe. Dublin: European Foundation for the Improvement of Living and Working Conditions.

Chamlin, M. B., \& Cochran, J. K. (2006). Economic inequality, legitimacy, and cross-national homicide rates. Homicide Studies, 10(4), 231-252. https://doi.org/10.1177/1088767906292642.

Croon, M. A., \& van Veldhoven, M. J. P. M. (2007). Predicting group-level outcome variables from variables measured at the individual level: A latent variable multilevel model. Psychological Methods, 12(1), 45-57. https://doi.org/10.1037/1082-989X.12.1.45.

Dafermos, Y., \& Papatheodorou, C. (2013). What drives inequality and poverty in the EU? Exploring the impact of macroeconomic and institutional factors, International Review of Applied Economics, 27(1), $1-22$.

Davey Smith, G. (1996). Income inequality and mortality: Why are they related? BMJ, 312(7037), 987.

Deaton, A. (2008). Income, health and wellbeing around the world: Evidence from the Gallup World Poll. Journal of Economic Perspectives, 22(2), 53-72.

Delhey, J., \& Dragolov, G. (2014). Why inequality makes Europeans less happy: The role of status anxiety, distrust, and conflicts. European Sociological Review, 30(2), 151-165.

Delhey, J., \& Dragolov, G. (2016). Happier together. Social cohesion and subjective well-being in Europe. International Journal of Psychology, 51(3), 163-176.

Delhey, J., \& Newton, K. (2005). Predicting cross-national levels of social trust: Global pattern or Nordic exceptionalism? European Sociological Review, 21(4), 311-327.

Delhey, J., Schneickert, C., \& Steckermeier, L. C. (2017). Sociocultural inequalities and status anxiety: Redirecting the spirit level theory. International Journal of Comparative Sociology, 58(3), 215-240.

Delhey, J., \& Steckermeier, L. C. (2016). The good life, affluence and self-reported happiness: Introducing the Good Life Index and debunking two popular myths. World Development, 88, 50-66.

Dragolov, G., Ignáz, Z., Lorenz, J., Delhey, J., Boehnke, K., \& Unzicker, K. (2016). Social cohesion in the western world. What holds societies together: Insights from the social cohesion radar. Springer briefs in well-being and quality of life research. Cham, Switzerland: Springer International.

Easterlin, R. A., \& Angelescu, L. (2012). Modern economic growth and quality of life: Cross-sectional and time-series evidence. In K. C. Land, A. C. Michalos, \& M. J. Sirgy (Eds.), Handbook of social indicators and quality of life (pp. 113-136). New York: Springer.

Eckersley, R. (2012). Whatever happened to Western civilization? The Futurist, 46(6), 16-22.

Elchardus, M., \& De Keere, K. (2013). Social control and institutional trust: Reconsidering the effect of modernity on social malaise. The Social Science Journal, 50(1), 101-111.

Elgar, F. J., \& Aitken, N. (2011). Income inequality, trust and homicide in 33 countries. The European Journal of Public Health, 21(2), 241-246.

Elgar, F. J., Craig, W., Boyce, W., Morgan, A., \& Vella-Zerb, R. (2009). Income inequality and school bullying: Multilevel study of adolescents in 37 countries. Journal of Adolescent Health, 45(4), 351-359.

Fantom, N. J., \& Serajuddin, U. (2016). The World Bank's classification of countries by income. World Bank Policy Research Working Paper No. 7528. Washington, DC: World Bank.

Ferreira, F. H. G., \& Ravallion, M. (2009). Poverty and inequality: The global inequality. In W. Salverda, B. Nolan, \& T. Smeeding (Eds.), The Oxford handbook of economic inequality (pp. 599-636). Oxford: Oxford University Press.

Grusky, D. B. (2001). Social stratification. In N. J. Smelser \& P. B. Baltes (Eds.), International encyclopedia of the social and behavioral sciences (Vol. 21, pp. 14443-14452). Amsterdam: Elsevier.

Hagerty, M. R., \& Veenhoven, R. (2003). Wealth and happiness revisited: Growing national income does go with greater happiness. Social Indicators Research, 64(1), 1-27.

Hewlett, N. (2011). The attack on the spirit level. Concept, 2(2), 18-24.

Hill, T. D., \& Jorgenson, A. (2018). Bring out your dead!: A study of income inequality and life expectancy in the United States, 2000-2010. Health and Place, 49, 1-6.

$\mathrm{Hu}$, Y., van Lenthe, F. J., \& Mackenbach, J. P. (2015). Income inequality, life expectancy and cause-specific mortality in 43 European countries, 1987-2008: A fixed effects study. European Journal of Epidemiology, 30(8), 615-625.

Inglehart, R. (1997). Modernization and postmodernization. Cultural, economic, and political change in 43 societies. Princeton, NJ: Princeton University Press.

Inglehart, R., \& Welzel, C. (2005). Modernization, cultural change and democracy. The human development sequence. New York, NY: Cambridge University Press.

Judge, K., Mulligan, J. A., \& Benzeval, M. (1998). Income inequality and population health. Social Science and Medicine, 46(4), 567-579. 
Kawachi, I. (2000). Income inequality and health. In L. F. Berkman \& I. Kawachi (Eds.), Social epidemiology (pp. 76-94). New York: Oxford University Press.

Kawachi, I., \& Berkman, L. F. (2000). Social cohesion, social capital, and health. In L. F. Berkman \& I. Kawachi (Eds.), Social epidemiology (pp. 174-190). New York: Oxford University Press.

Kelley, J., \& Evans, M. D. R. (2017). Societal inequality and individual subjective well-being: Results from 68 societies and over 200,000 individuals, 1981-2008. Social Science Research, 62, 1-23. https://doi. org/10.1016/j.ssresearch.2016.04.020.

Kennelly, B., O'Shea, E., \& Garvey, E. (2003). Social capital, life expectancy and mortality: A crossnational examination. Social Science and Medicine, 56(12), 2367-2377. https://doi.org/10.1016/S0277 $-9536(02) 00241-1$.

Kragten, N., \& Rözer, J. (2017). The income inequality hypothesis revisited: Assessing the hypothesis using four methodological approaches. Social Indicators Research, 131(3), 1015-1033. https://doi. org/10.1007/s11205-016-1283-8.

LaFree, G., \& Tseloni, A. (2006). Democracy and crime: A multilevel analysis of homicide trends in fortyfour countries, 1950-2000. The Annals of the American Academy of Political and Social Science, $605(1), 25-49$.

Lancee, B., \& van de Werfhorst, H. G. (2012). Income inequality and participation: A comparison of 24 European countries. Social Science Research, 41, 1166-1178.

Layte, R. (2012). The association between income inequality and mental health: Testing status anxiety, social capital, and neo-materialist explanations. European Sociological Review, 28(4), 498-511.

Leigh, A., \& Jencks, C. (2007). Inequality and mortality: Long-run evidence from a panel of countries. Journal of Health Economics, 26(1), 1-24.

Lynch, J., Smith, G. D., Harper, S., \& Hillemeier, M. (2004a). Is income inequality a determinant of population health? Part 2. US national and regional trends in Income inequality and age-and cause-specific mortality. The Milbank Quarterly, 82(2), 355-400.

Lynch, J., Smith, G. D., Harper, S. A., Hillemeier, M., Ross, N., Kaplan, G. A., et al. (2004b). Is income inequality a determinant of population health? Part 1. A systematic review. The Milbank Quarterly, 82(1), 5-99.

Merton, R. K. (1938). Social structure and anomie. American Sociological Review, 3, 672-682.

Mills, C. (2012). Open letter to Prof. Richard Wilkinson and Prof. Kate Pickett (Vol. 2013). Oxford: Oxford Sociology Blog.

Neumayer, E., \& Plümper, T. (2016). Inequalities of income and inequalities of longevity: A cross-country study. American Journal of Public Health, 106(1), 160-165.

O'Connell, M. F. (2010). Affluence versus equality? A critique of Wilkinson and Pickett's book 'The Spirit Level'. School of Psychology Research Collection. Dublin: University College Dublin.

Offer, A. (2006). The challenge of affluence. Self-control and well-being in the United States and Britain since 1950. Oxford: Oxford University Press.

Paskov, M., \& Dewilde, C. (2012). Income inequality and solidarity in Europe. Research in Social Stratification and Mobility, 30, 415-432.

Paskov, M., Gerxhani, K., \& van de Werfhorst, H. G. (2017). Giving up on the Joneses? The relationship between income inequality and status-seeking. European Sociological Review, 33(1), 112-123.

Phillips, D. (2006). Quality of life. Concept, policy and practice. London, New York: Routledge.

Pop, I. A., van Ingen, E., \& Van Oorschot, W. (2013). Inequality, wealth and health: Is decreasing income inequality the key to create healthier societies? Social Indicators Research, 113, 1025-1043.

Rambotti, S. (2015). Recalibrating the spirit level: An analysis of the interaction of income inequality and poverty and its effect on health. Social Science and Medicine, 139, 123-131. https://doi.org/10.1016/j. socscimed.2015.02.026.

Rodgers, G. B. (1979). Income and inequality as determinants of mortality: An international cross-section analysis. Population Studies, 33(2), 343-351.

Rohrbach, D. (2009). Sector bias and sector dualism. The knowledge society and inequality. International Journal of Comparative Sociology, 50(5-6), 510-536.

Saunders, P., \& Evans, N. (2010). Beware false prophets. Equality, the good society and the spirit level. London: Policy Exchange.

Shkolnikov, V. M., Andreev, E. M., Zhang, Z., Oeppen, J., \& Vaupel, J. W. (2011). Losses of expected lifetime in the United States and other developed countries: Methods and empirical analyses. Demography, 48(1), 211-239.

Skidelsky, R., \& Skidelsky, E. (2013). How much is enough? Money and the good life. London: Penguin Books.

Snowdon, C. (2010). The spirit level delusion: Fact-checking the left's new theory of everything. Ripon, UK: Little Dice. 
Solt, F. (2016a). The standardized world income inequality database. Social Science Quarterly, 97(5), $1267-1281$.

Solt, F. (2016b). Using the SWIID in Stata. Unpublished manuscript, University of Iowa. https://dataverse. harvard.edu/dataset.xhtml?persistentId=doi:10.7910/DVN/LM4OWF. Accessed 10 Sept 2019.

Steckermeier, L. C., \& Delhey, J. (2019). Better for everyone? Egalitarian culture and social wellbeing in Europe. Social Indicators Research, 143(3), 1075-1108.

Steijn, S., \& Lancee, B. (2011). Does income inequality negatively affect general trust? GINI Discussion Paper 20. Amsterdam: AISA.

Su, D., Esqueda, O. A., Li, L., \& Pagán, J. A. (2011). Income inequality and obesity prevalence among OECD countries. Journal of Biosocial Science, 44(4), 417-432. https://doi.org/10.1017/S002193201 $100071 X$.

Subramanian, S. V., \& Kawachi, I. (2004). Income inequality and health: What have we learned so far? Epidemiologic Reviews, 26(1), 78-91.

Sutton, J. R. (2004). The political economy of imprisonment in affluent western democracies, 1960-1990. American Sociological Review, 69(2), 170-189.

Torre, R., \& Myrskylä, M. (2014). Income inequality and population health: An analysis of panel data for 21 developed countries, 1975-2006. Population Studies, 68(1), 1-13.

van Deurzen, I., van Ingen, E., \& van Oorschot, W. J. H. (2015). Income inequality and depression: The role of social comparisons and coping resources. European Sociological Review, 31(4), 477-489.

Vogli, R. D., Kouvonen, A., Elovainio, M., \& Marmot, M. (2014). Economic globalization, inequality and body mass index: A cross-national analysis of 127 countries. Critical Public Health, 24(1), 7-21.

Welzel, C. (2013). Freedom rising. Human empowerment and the quest for emancipation. Cambridge, UK: Cambridge University Press.

Whelan, C., \& Layte, R. (2014). Who feels inferior? A test of the status anxiety hypothesis of social inequalities in health. European Sociological Review, 30(4), 525-535.

Whelan, C. T., \& Maitre, B. (2013). Material deprivation, economic stress, and reference groups in Europe: An analysis of EU-SILC 2009. European Sociological Review, 29(6), 1162-1174. https://doi. org/10.1093/esr/jct006.

Wilkinson, Richard. (1996). Unhealthy societies: The afflictions of inequality. London: Routledge.

Wilkinson, R. (1999). Income inequality, social cohesion, and health: Clarifying the theory-A reply to Muntaner and Lynch. International Journal of Health Services, 29(3), 525-543. https://doi. org/10.2190/3qxp-4n6t-n0qg-ecxp.

Wilkinson, R., \& Pickett, K. (2010). The spirit level: Why more equal societies always do better. London: Penguin Books.

Wilkinson, R., \& Pickett, K. (2017). The enemy between us: The psychological and social costs of inequality. European Journal of Social Psychology, 47, 11-24.

Zagorski, K., Evans, M. D., Kelley, J., \& Piotrowska, K. (2014). Does national income inequality affect individuals' quality of life in Europe? Inequality, happiness, finances, and health. Social Indicators Research, 117(3), 1089-1110.

Publisher's Note Springer Nature remains neutral with regard to jurisdictional claims in published maps and institutional affiliations. 